\title{
Research on Comfort Evaluation Model of Urban Residents' Public Space Lighting Integrating Public Perception and Nighttime Light Remote Sensing Data
}

\author{
Shengrong Wei ${ }^{1,2,3,4} \mathbb{D}$, Weili Jiao ${ }^{1,2,5}$, Huichan Liu ${ }^{1,5}$, Tengfei Long ${ }^{1,5} \mathbb{D}$, Yongkun Liu ${ }^{1,2} \mathbb{D}$, Ping Ji $^{3,4}$, \\ Ruixia Hou ${ }^{3,4}$, Naijing Zhang ${ }^{3,4}$ and Yundan Xiao ${ }^{3,4, *}$
}

check for

updates

Citation: Wei, S.; Jiao, W.; Liu, H.; Long, T.; Liu, Y.; Ji, P.; Hou, R.; Zhang, N.; Xiao, Y. Research on Comfort Evaluation Model of Urban Residents' Public Space Lighting Integrating Public Perception and Nighttime Light Remote Sensing Data. Remote Sens. 2022, 14, 655 https://doi.org/10.3390/ rs14030655

Academic Editors: Anna Visvizi, Wadee Alhalabi, Shahira Assem Abdel Razek, Paolo Gerli and Orlando Troisi

Received: 24 November 2021

Accepted: 26 January 2022

Published: 29 January 2022

Publisher's Note: MDPI stays neutral with regard to jurisdictional claims in published maps and institutional affiliations.

Copyright: (C) 2022 by the authors. Licensee MDPI, Basel, Switzerland. This article is an open access article distributed under the terms and conditions of the Creative Commons Attribution (CC BY) license (https:// creativecommons.org/licenses/by/ $4.0 /$ )
1 Aerospace Information Research Institute, Chinese Academy of Sciences (CAS), Beijing 100094, China; weisr@ifrit.ac.cn (S.W.); jiaowl@aircas.ac.cn (W.J.); liuhc@aircas.ac.cn (H.L.); longtf@aircas.ac.cn (T.L.); liuyk@aircas.ac.cn (Y.L.)

2 College of Resources and Environment, University of Chinese Academy of Sciences, Beijing 100049, China

3 Institute of Forest Resource Information Techniques, Chinese Academy of Forestry (CAF), Beijing 100091, China; jiping@ifrit.ac.cn (P.J.); houreix@ifrit.ac.cn (R.H.); zhangnaijing@ifrit.ac.cn (N.Z.)

4 Key Laboratory of Forestry Remote Sensing and Information System, National Forestry and Grassland Administration, Beijing 100091, China

5 Hainan Key Laboratory for Earth Observation, Sanya 572029, China

* Correspondence: xiaoyd@ifrit.ac.cn

\begin{abstract}
With the development of a sustainable lifestyle, people are paying more and more attention to the comfort of their own living environment, including public space lighting, which is immediately accessible to residents. The demand on its quality and comfort has thus gained attention recently. However, there is still a lack of related research on public space lighting comfort evaluation models that combine nighttime light remote sensing data and field measurement data, and link lighting attributes with the comfort of residents. This research uses nighttime light remote sensing data to select typical test areas, measures the lighting data of the survey points on the spot, develops an intelligent WeChat applet that collects public perception data, analyzes different lighting parameters, and builds a public space lighting comfort model based on the structural equation model analysis method. The results show that the factor that the areas with high light intensity are more comfortable than the areas with low light intensity. In areas with high light intensity, people pay more attention to the uniformity, security and comfort of the light, while in areas with low light intensity or high blue light, people's perception of glare will be more obvious. This research can provide a basis for the intelligent optimization of public space lighting from the perspective of public preference.
\end{abstract}

Keywords: public perception; nighttime light remote sensing; public space lighting; user-oriented interactive questionnaire; comfort evaluation model

\section{Introduction}

As an important part of urban life, public space lighting directly affects people's perception and activities, plays an important role in shaping the image of urban night scenery and showing the achievements of urban development. The main beneficiaries of public space lighting are the general public. The sensitivity of urban residents' perception of space lighting speeds up and promotes the development of space lighting. Additionally, the development of public space lighting technology promotes and supports people to move forward to a higher quality of life.

With the development of people-oriented thinking and sustainable lifestyle [1], people are paying more and more attention to the comfort of their own living environment. As one of the easiest living environments to be intuitively felt, residents have put forward higher requirements for the comfort of light environment. This is not only to respond to the policy and conform to the trend of social development, but also because the lighting 
environment of public space will have a certain impact on people's physiology and psychology. The quality of the lighting environment will directly or indirectly affect people's emotions, preferences, entertainment, stimulation and so on, and further affect people's behavior. For example, dazzling glare will cause visual fatigue and even headaches and other discomfort [2-5].

There are many methods and viewpoints about light environment evaluation. Many studies have shown that the indicators affecting lighting quality, such as illumination, color temperature and glare, have a direct relationship with the evaluation of light environment, and can comprehensively affect the visual function of residents. Antonio Peña-García et al. evaluated user perceptions of the impact of different kinds of public lighting on perceived safety from criminal actions and on general well-being [6]. Liu Ming et al. showed that factors affecting residents' perception of outdoor public space lighting may also be influenced by pedestrians' own characteristics and social and economic factors in addition to lighting attributes such as illumination, color temperature, uniformity and glare index [7]. Boris A. Portnov et al. linked different PSL (public space lighting) attributes with residents' feeling of safety through investigation, statistics and regression model methods [8].

The development of nighttime light remote sensing provides more possibilities for the lighting comfort evaluation of urban residents. Nighttime light can directly reflect human activities and is highly correlated with the degree of social and economic development $[9,10]$. Therefore, it is mostly used to evaluate social and economic indicators [11,12], major events [13,14], criminological research [15-18], carbon emission indicators [19] and ecological and environmental effects [20-23]. Nighttime light remote sensing imaging has the advantages of rich data, high efficiency and intuitive, and wide coverage [21,24], provided an objective basis for the research on lighting comfort of urban public space with its unique perspective. However, so far, there is still a lack of relevant studies on the lighting experience evaluation model of public space, which combines nighttime light remote sensing data, considers various background factors, and connects lighting attributes with residents' comfort [25].

Based on these, this paper adopts a user-oriented interactive questionnaire method based on WeChat applets to obtain public perception data. Professional lighting measuring instruments are used to measure the lighting attributes of the survey points on the outdoor routes of typical residential areas. The high-resolution nighttime light remote sensing images of the International Space Station (ISS) and the Chinese satellite program Jilin-1 (JL1) are used to select typical residential areas and to analyze the results of the evaluation model. From the perspective of sky, earth and people, the lighting attributes such as light illuminance, color temperature, uniformity and glare index are linked with comfort, and fed back to the objective nighttime light remote sensing data, so as to obtain a public space lighting comfort evaluation model more in line with the public's subjective feeling.

\section{Materials and Methods}

\subsection{Research Areas and Data Sources}

\subsubsection{Research Areas}

As the capital of China, Beijing is the center of politics, culture, international exchanges and scientific and technological innovation in China [26,27]. The development of its nighttime lighting is representative and instructive to Chinese cities. It is of great value to study the evaluation of urban residents' space lighting comfort for improving people's life satisfaction and promoting the sustainable development of social economy.

There are 16 municipal districts in Beijing. Among them, Dongcheng District and Xicheng District, the core functional area of the capital, and Chaoyang District, Haidian District, Fengtai District and Shijingshan District, the urban functional expansion area, are the six districts in the center of Beijing. The area of the six districts only accounts for about $8.4 \%$ of the total area of Beijing, but the population of them accounts for $52.2 \%$ of the permanent population of Beijing, with an average population density of more than 8000 people per square kilometer (Figure 1). As the research areas of this paper, the 
six districts of Beijing have more abundant nighttime light data, and the distribution of nighttime light of residential areas is relatively uniform and more representative.

Research area and population distribution of Beijing

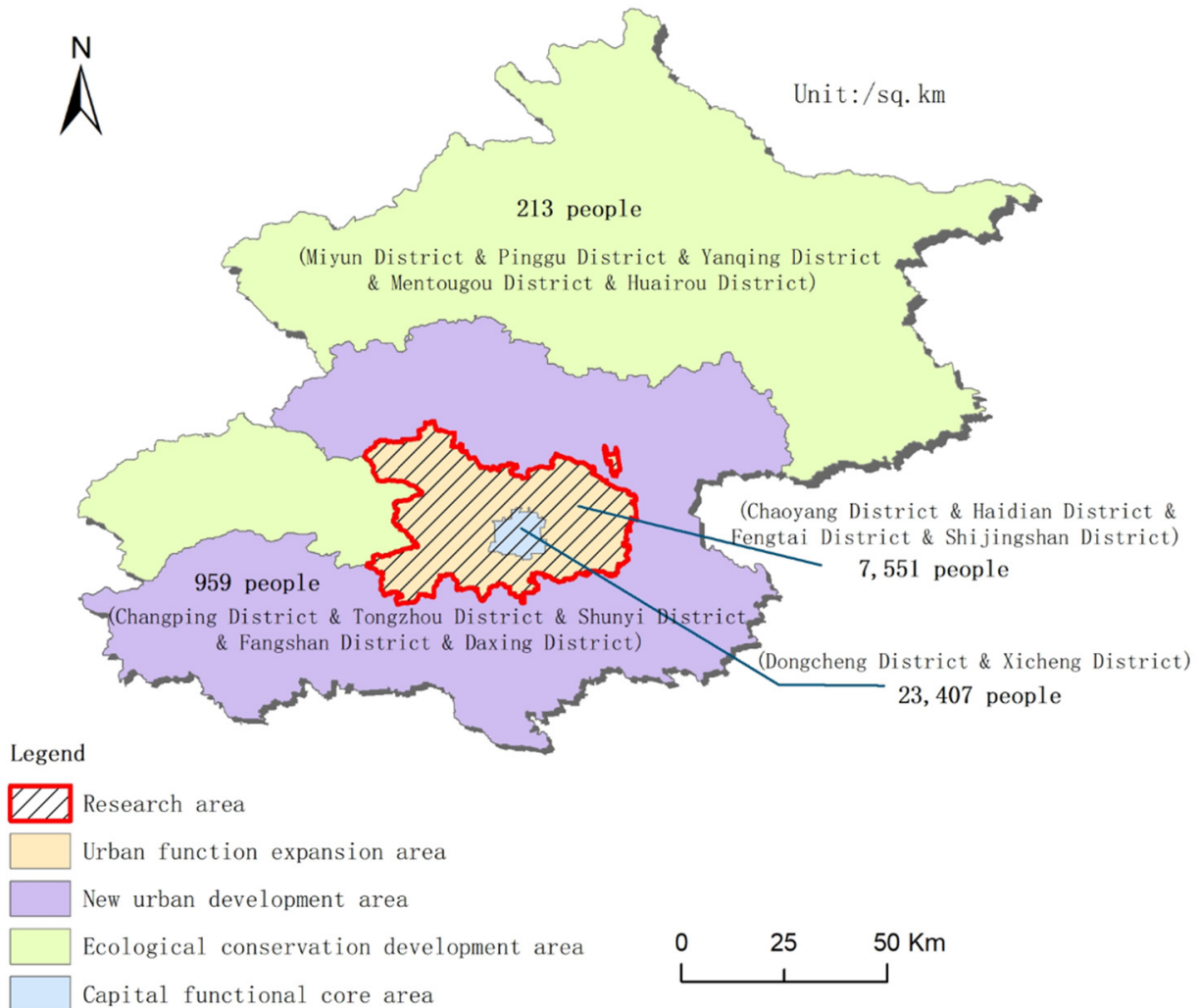

Figure 1. Research area and population distribution of Beijing.

\subsubsection{Nighttime Light Remote Sensing Data}

Because the DMSP/OLS (Defense Meteorological Satellite Program/Operational Linescan System) and VIIRS/DNB (Visible Infrared Imaging Radiometer Suite Day/Night Band) nighttime remote sensing images have relatively low resolution and only have a panchromatic band, they have certain limitations in their application to small-scale urban research [9]. This research is based on small spatial-scale city lights, using high-resolution multi-spectral night remote sensing images, namely the International Space Station RGB nighttime light image [28,29] and Jilin-1 RGB nighttime light remote sensing image of [30].

The ISS nighttime light image used in this paper was taken by astronauts using Nikon D3S electronic still camera during the 26 Mission. It was taken at 14:34:43 GMT on 14 December 2010. In the ISS nighttime image of the study area, after geometric registration and relative radiation normalization by Wei Shengrong et al. [31], the signal-to-noise ratio increases, and the oversaturation phenomenon decreases (Figure 2b). The ISS image, with a spatial resolution of $50 \mathrm{~m}$ and three bands of red, green and blue, can support the research of this paper. It can clearly reflect the nighttime lighting situation of typical residential areas at street level $[9,28,32]$. 


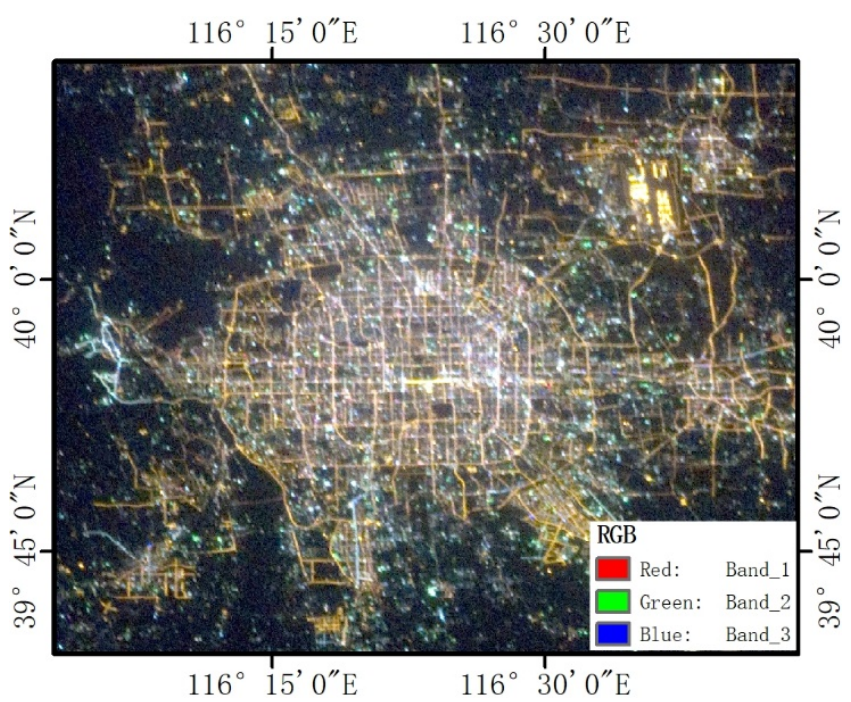

(a)

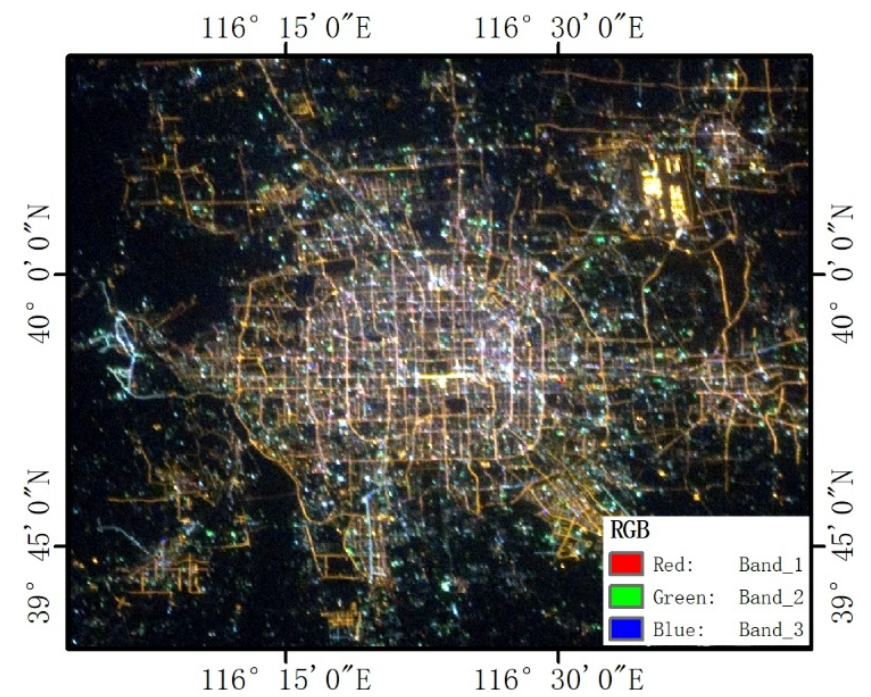

(b)

Figure 2. Before (a) and after (b) relative radiation normalization of International Space Station multi-spectral nighttime light image in Beijing area.

Compared with the ISS nighttime light image, the Jilin-1 commercial satellite nighttime light remote sensing data has a higher spatial resolution of $1 \mathrm{~m}$. However, due to its small single scene image size, limited archived data and high price, it did not have full coverage in Beijing during the research period of this paper. The use of multi-scene Jilin-1 data requires higher geometric registration and radiometric correction accuracy. Therefore, this research does not use Jilin-1 data as the main nighttime light data source.

The Jilin-1 nighttime light remote sending images were collected in 2019-2020, which may be more consistent with the current lighting situation, so they were used as auxiliary nighttime light data sources. The data shown in Figure 3 was mosaicked by processing 7 scenes of nighttime light remote sensing images taken by JL1-3B and JL1-7B satellites in 2019-2020, among which the southwest area of Beijing lacks archived Jilin-1 nighttime light remote sensing images (data as of 2020) [33]. The preprocessing process of Jilin-1 nighttime light remote sensing image was mainly divided into the following three steps:

1. Firstly, the optical remote sensing image with $2 \mathrm{~m}$ resolution of research area was used for geometric registration for each scene of Jilin-1 nighttime light remote sensing image [34]. The matching points of Jilin-1 nighttime light image and optical remote sensing image were identified by locating road intersections, overpass hubs, landscape boundaries, street lights, building shapes, etc., so as to realize the geometric registration of Jilin-1 images.

2. Secondly, the overlapping areas between the 7 scene images were used to perform relative radiation correction. One scene Jilin-1 nighttime light image was taken as the reference image, and other images adjacent to it with overlapping areas as the target image for relative radiation correction. The method of relative radiation correction [31] was as follows: the overlapping areas of nighttime light remote sensing data were extracted, and the radiation correction models of the three bands of red, green and blue in the overlapping areas were constructed, and then the obtained models were used, respectively, for the radiation correction of the corresponding images.

3. Finally, 7 Jilin-1 nighttime light remote sensing images after the completion of geographic registration and radiometric correction were mosaicked into a scene nighttime light remote sensing image of Beijing area (Figure 3). This image has a spatial resolution of $1 \mathrm{~m}$, a pixel depth of 8 bits, and three bands of red, green and blue information. 


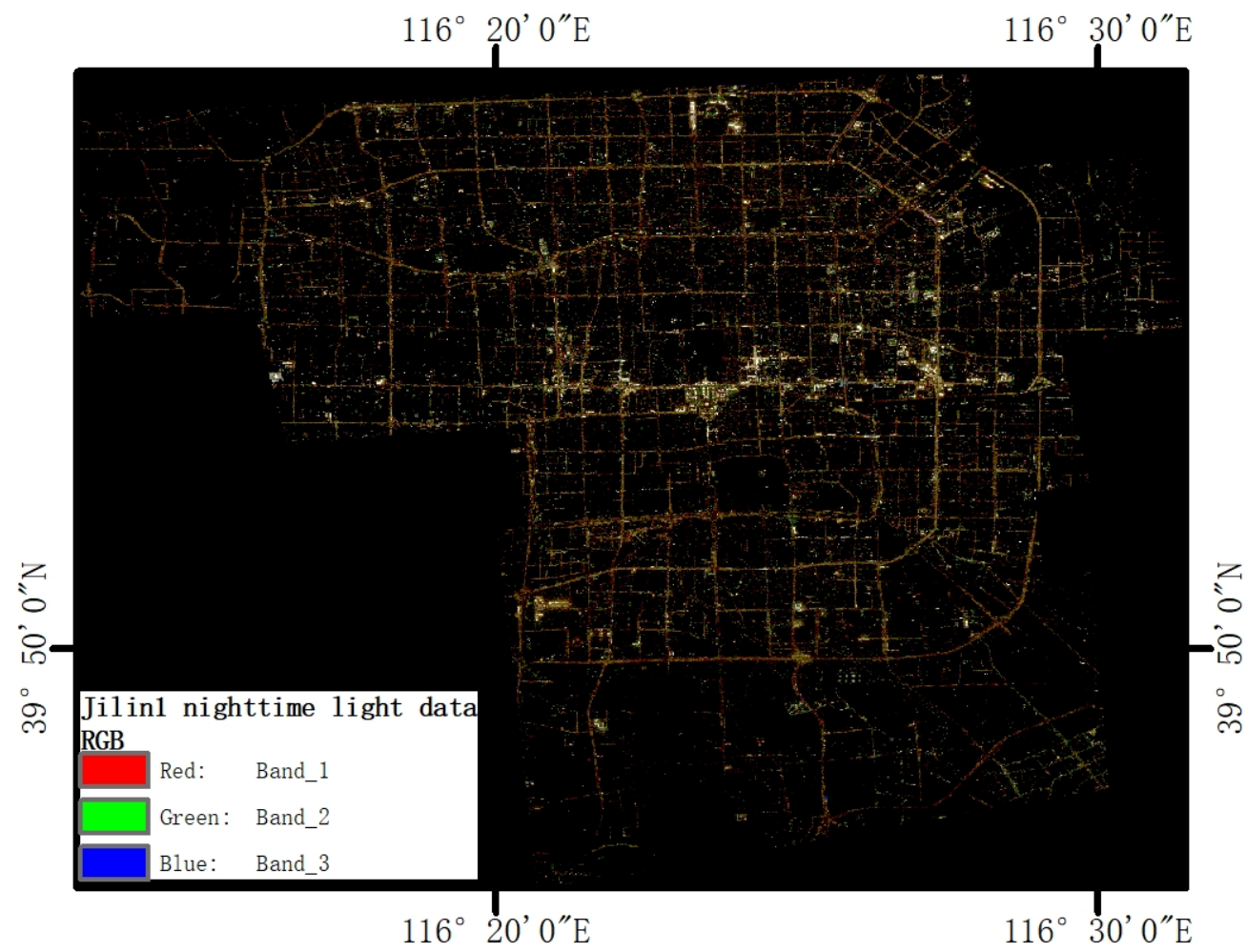

Figure 3. The Jilin-1 archived nighttime light remote sensing data of Beijing (data as of 2020).

\subsubsection{Vector Data}

The vector map of Beijing used in this paper was the administrative level vector data of township (street) obtained by spatial topology analysis. The same geographic coordinate system and the WGS-1984 projection coordinate system were assigned to the vector data of township and relative radiation normalized nighttime light data. The attribute information of vector file includes coordinate position information of each unit, administrative boundary outline, area size of each unit and spatial relationship between each vector unit, etc. The vector data range is included in the range of scenes taken from the International Space Station nighttime light images used.

\subsubsection{Socioeconomic Data}

From the perspective of social and economic parameters, this paper combined the Beijing Statistical Yearbook and the sixth national population census to obtain the area, permanent population, population educational level and other social and economic data of each township in the six districts of Beijing. The population density index (PDI, unit nit: people per sq. $\mathrm{km}$ ) and the proportion of the population with junior school education or above (defined as education index (EI) with a value range of 0 to 1 ) were calculated.

\subsection{The Selection Method of Typical Residential Areas in Beijing}

Typical residential areas in Beijing were selected in the vector map of township (street) level by using nighttime light remote sensing data and socioeconomic data.

Firstly, the social and economic parameters are associated with the corresponding units of the vector map, and the natural break (Jenks) method was used to divide the vector map into five classes, respectively, to ensure the minimum difference (variance) within the class and the maximum difference (variance) between the classes. Based on this, the education index (EI) and population density index (PDI) of the township level in the study area were visualized on the bottom layer of vector data (Figure 4). 


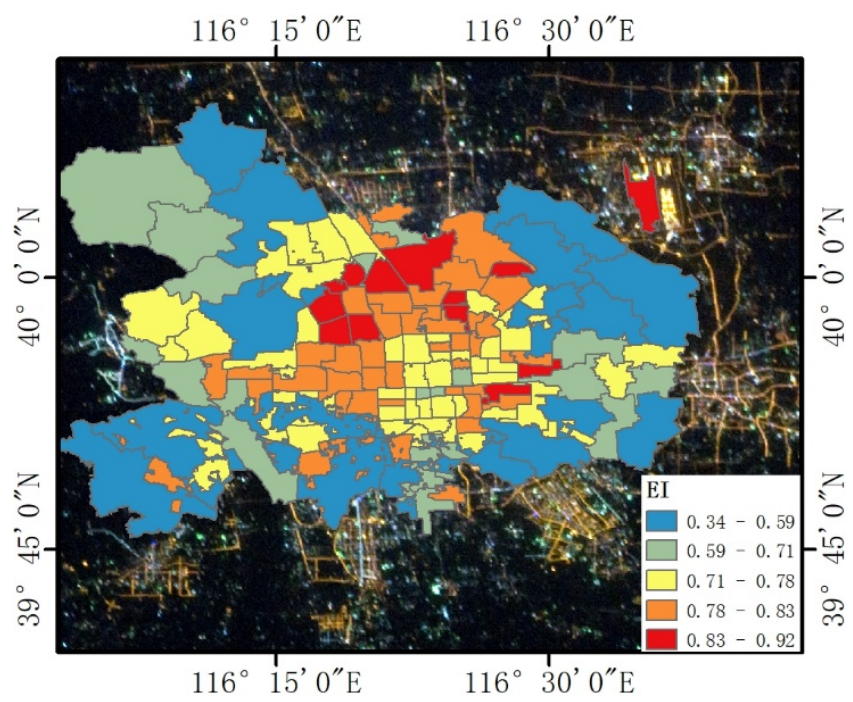

(a)

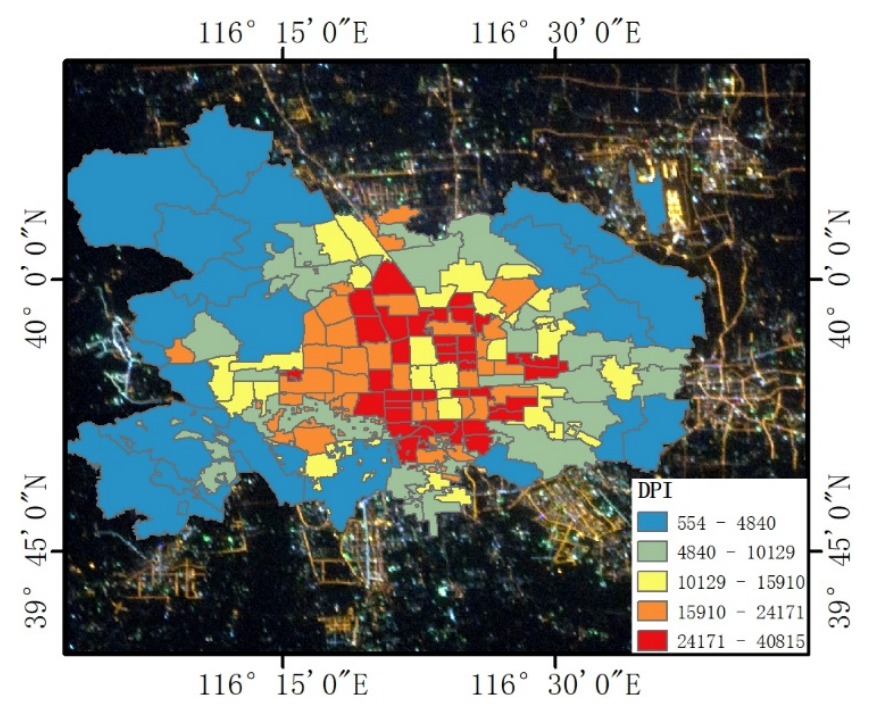

(b)

Figure 4. The proportion of the population with junior school education and above (EI) (a) and the distribution of population density index (PDI) (b) in the research area.

Secondly, the ISS nighttime light remote sensing image of Beijing research area was used to analyze nighttime light brightness. The mean DN values of the red and blue light of the ISS nighttime light image pixels contained in each unit were obtained based on the statistics of the township vector layer. The red light and blue light intensities were divided into five classes by the natural break method, which were the same as the classification of socio-economic parameters to ensure the minimum difference within the class and the maximum difference between the classes (Figure 5). Based on the statement in Section 2.1.2, the red and blue light of Jilin-1 satellite nighttime light remote sensing data were analyzed, and the method was the same as that of ISS nighttime light image processing.

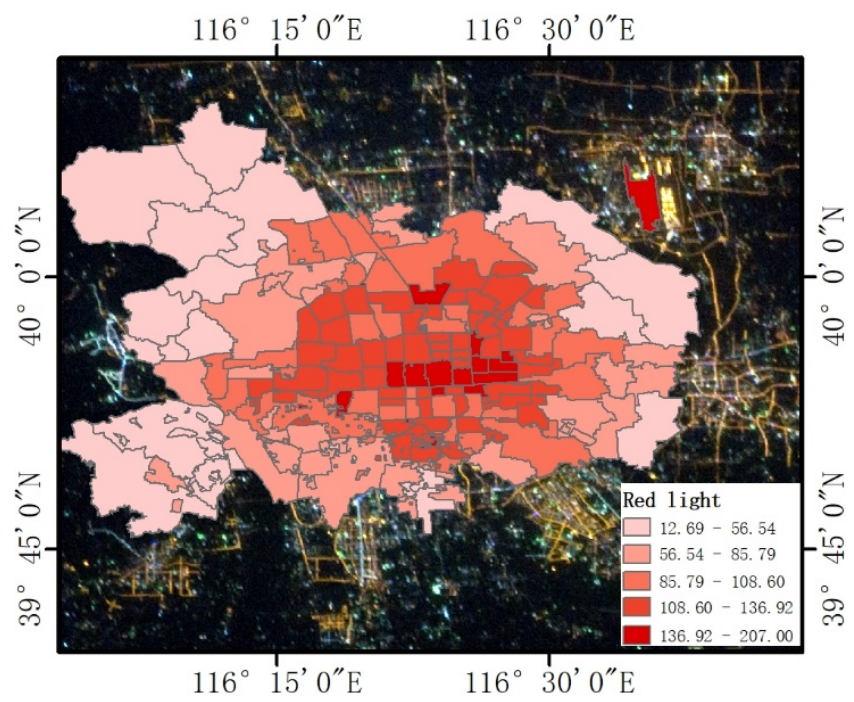

(a)

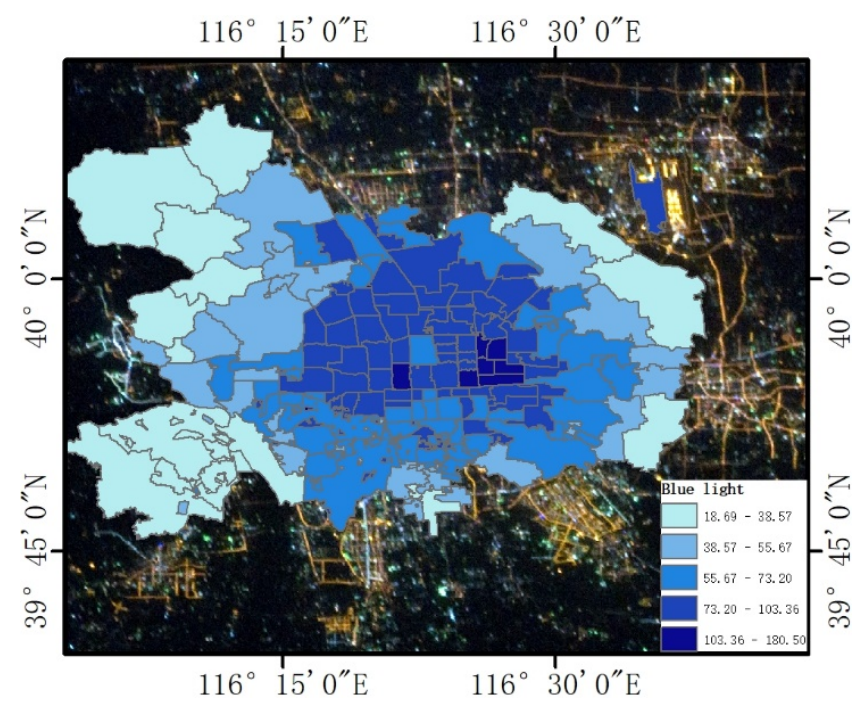

(b)

Figure 5. Classification results of red (a) and blue (b) light intensities by natural breaks method in the research area.

Thirdly, townships (streets) with EI higher than 0.7 and PDI higher than 15,000 were selected as alternative areas. Then, townships with moderate area and meeting the requirements of high red light, high blue light, low red light and low blue light, respectively, were selected from these alternative areas. 
Finally, some townships with more commercial areas or more park landscapes were removed by using high-resolution optical remote sensing data. In the remaining townships, four different townships (streets) as the typical residential areas were finally selected. They are Jinrongjie street (high blue light), Chongwenmenwai street (high red light), Chunshu street (low red light) and Beitaipingzhuang street (low blue light) (Figure 6). These four typical residential areas are prepared for the formulation of field survey routes and survey sites.

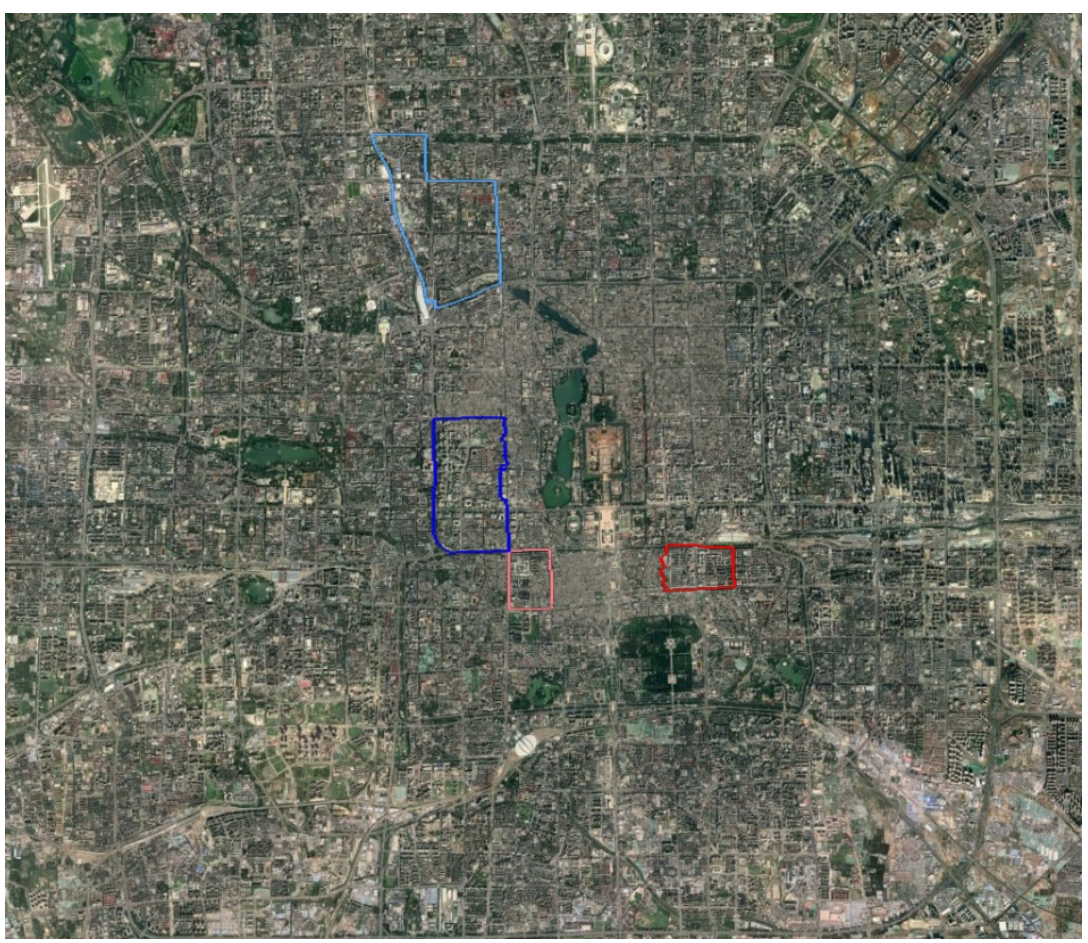

Figure 6. The spatial location of four typical residential areas. Jinrongjie street (high blue light), Chongwenmenwai street (high red light), Chunshu street (low red light) and Beitaipingzhuang street (low blue light).

\subsection{Field Measurement Method}

The measurement and survey route of typical residential areas were planned through high-resolution remote sensing images, land use types and field research results.

The roads to be measured and surveyed in four typical residential areas were determined based on the field investigation. According to the principle of passing through residential areas as much as possible and walking on the right, a survey route of 800 1000 m was planned in each residential area, covering main streets, secondary streets and open spaces. In addition to intersections and community entrances and exits, the spacing between $12 \mathrm{~m}$ high street lamps on the road is about $30 \mathrm{~m}$, the spacing between $8 \mathrm{~m}$ high lamps is about $20 \mathrm{~m}$, and the spacing between $6 \mathrm{~m}$ high lamps is about $15 \mathrm{~m}$. In addition, there are differences in the type and wattage of street lamps, road level, double arm lamps and single arm lamps. In order to ensure that each survey point that the respondents walk to keep a different distance from the street lamps as far as possible, random discrete points with an interval of about $40 \sim 70 \mathrm{~m}$ on the route were selected as the measurement and survey points [8]. Figure 7 showed the survey points and survey route of the Chongwenmenwai street as an example. 


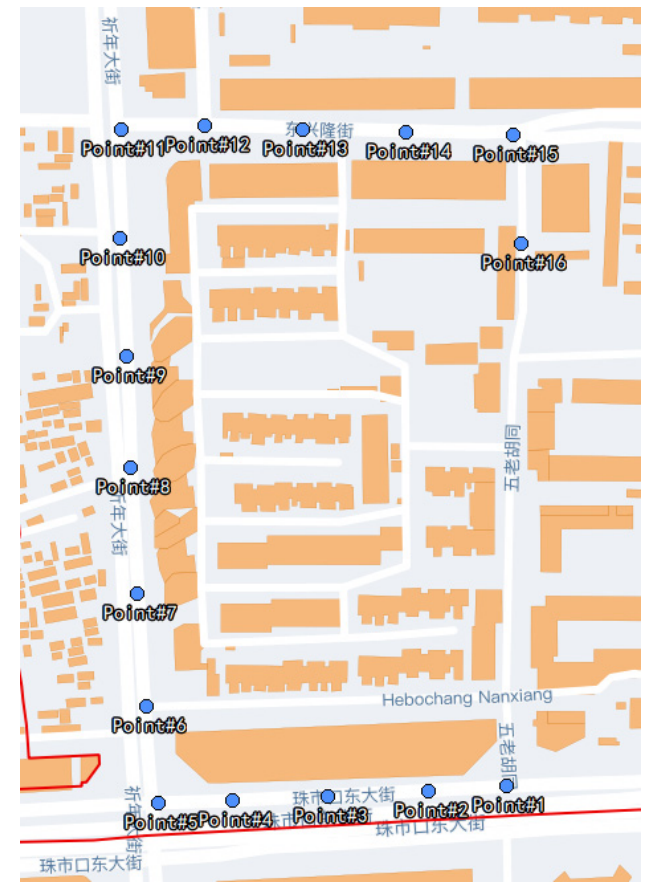

Figure 7. Chongwenmenwai street typical residential area survey route and survey points designation.

Referring to the field measurement method of Boris et al., the following public space lighting attributes were measured at each survey point with the illuminance spectrophotometer CL-500A [7,8].

1. Illumination (Lux);

2. Color temperature (Kelvins, K);

For each light attribute, the following three separate measurement types will be taken:

1. The observer's line of sight height (approximately $1.5 \mathrm{~m}$ above the ground) (Figure 8a; $\mathrm{U} 1-\mathrm{U} 6$, as input parameters to the model);

2. Vertical measurement (Figure 8b; U7);

3. Ground level (Figure 8b; U8).

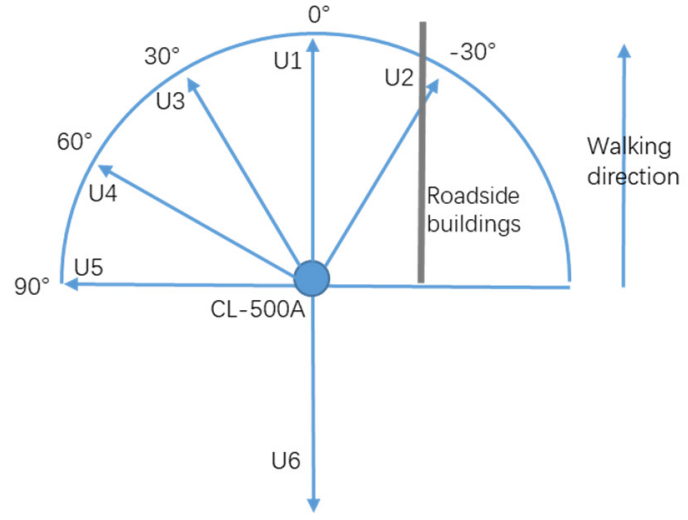

(a)

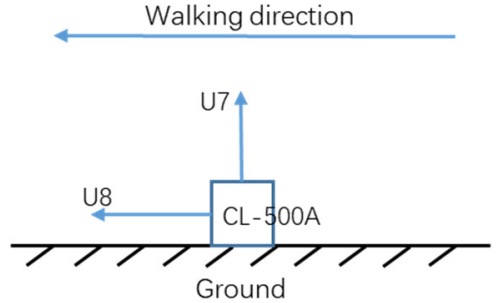

(b)

Figure 8. Field measurement method at each survey point. (a) The direction of measurement at the observer's line of sight height; (b) Direction of measurement on the ground.

In order to correspond to the input parameters of the evaluation model in this research, a code, such as U1, was added after each light attribute parameter. 
The standard deviation (Equation (1)) and the ratio of the minimum and maximum (Equation (2)) of the illuminance in the eight directions of U1-U8 (Figure 8) were calculated, and they were used as the input parameters of the model:

$$
\begin{gathered}
U n 1=\sqrt{\frac{\sum_{i=1}^{8}\left(U_{i}-\bar{U}\right)^{2}}{8}}, \\
U n 2=\frac{U_{\min }}{U_{\max }},
\end{gathered}
$$

where $U n 1$ is the standard deviation of the illuminance in the eight directions of $U 1-U 8$, $U n 2$ is the ratio of the minimum and maximum of the illuminance in the eight directions of U1-U8. U1-U8 are the light illuminance measurement values of each point.

The average value of light illuminance attributes of different directions was calculated as the average illuminance of the point:

$$
S 1=(U 1+U 2+U 3+U 4+U 5+U 6+U 7+U 8) / 8,
$$

where $S 1$ is the mean value of light illuminance in eight directions, $S 1$ is an input parameter of the comfort evaluation model.

LS-160 luminance meter can be used to measure the glare of the survey site. At each survey point along the route, the brightness of every major lighting device that falls within the observer's field of view as the observer walks along the sidewalk will be measured. The total illumination at each survey point will be the sum of the luminance generated by each illuminator:

$$
S 2=L_{v_{1}}+L_{v_{2}}+\ldots+L_{v_{n}},
$$

where $S 2$ is the light glare intensity of each point, and $n$ is the number of measured street lamps. $S 2$ is another parameter of the evaluation model.

CL-500A can also measure the color temperature of survey points on the route, which is expressed by $\mathrm{x}$-color temperature (range 0 to 1 ) and $\mathrm{y}$-color temperature (range 0 to 1 ). The hue range can be displayed as a curve on the CIE chromaticity diagram, which is called blackbody radiation trajectory (Planck trajectory). Figure 9 represents the position of the $x-y$ color temperature of one measurement in the CIE chromaticity space. It can be seen from the figure that the light source color of the measurement point is orange yellow, belonging to warm tone. The $\mathrm{x}$-color temperature and $\mathrm{y}$-color temperature are the input parameters of the evaluation model.
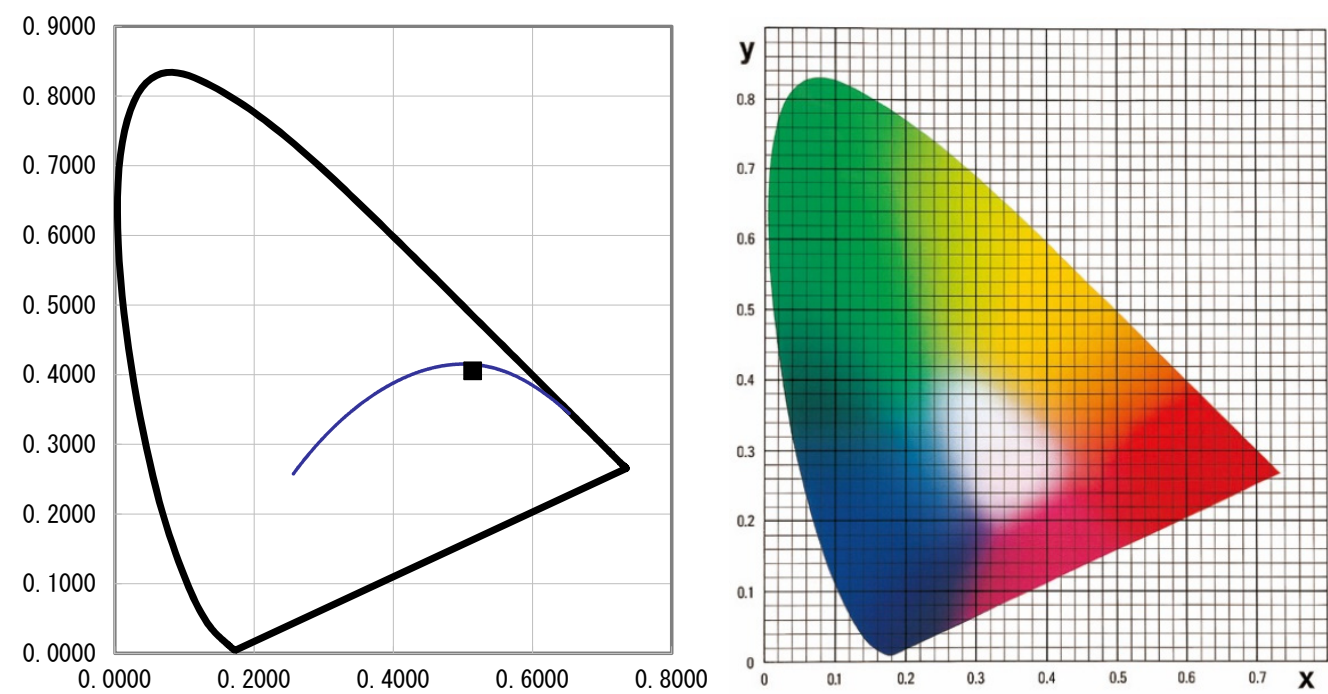

Figure 9. The $x-y$ color temperature of one measurement in the CIE chromaticity space. 
The on-site measurement and evaluation of lighting attributes were carried out on a cloudless winter night one hour after sunset (19:00 Beijing time; 11:00 GMT) to 24:00 (16:00 GMT).

\subsection{Public Perception Data Collection Method Based on WeChat Applet}

Data collection in this research is different from traditional "paper" questionnaires, but adopts an interactive survey method. By designing an intelligent WeChat applet with fast propagation speed and smooth usage, it is convenient for users to operate and improve user experience [35].

The applet has the advantages of more smooth use experience, more exposure opportunities, simple and quick use, easy retention of users and fast spread. This paper applies the applet (named "nighttime light survey") to intelligently collect residents' feeling index of public space lighting attributes, feeling of security and comfort on outdoor routes (a-f) of four typical residential areas in urban Beijing.

At each survey point, each respondent was required to submit the evaluation of illumination, color temperature, uniformity, glare, sense of security and overall comfort. According to the Likert scale, the uncertain option in the middle was removed to form a bipolar four-point scale and score the following six attributes [35]:

a. light intensity ( 0 - very weak; 1 -the weaker; 2-the stronger; 3 -very strong);

b. color temperature ( 0 - too cold; 1 -slants cold; 2-warm; 3-too warm);

c. uniformity (0-completely non-uniformity; 1 -slightly uneven; 2-slightly uniform; 3-very even);

d. glare (0-no glare; 1 -glare is not obvious; 2 - glare is slightly obvious; 3 - glare is very obvious);

e. feeling of security ( 0 - feeling very insecure; 1 -feeling slightly insecure; 2 -feeling a little safe; 3 -feeling very safe);

f. feeling of comfort (0-very uncomfortable; 1 -slightly uncomfortable; 2 -slightly comfortable; 3-very comfortable).

After completing the questionnaire survey at each point of a route, the interviewees will continue to fill in the feedback of the whole route, and evaluate the influence degree of the above four lighting attributes a-d on lighting comfort, respectively.

Respondents submitted their feelings about the lighting properties and comfort of public spaces following the pre-set routes and survey points in Section 2.3. The survey for each route takes about $20 \mathrm{~min}$. The information obtained includes gender, age, education level, evaluation time and date, and so on. The questionnaire sets the entry time from $1 \mathrm{~h}$ after sunset (19:00 Beijing time) to 24:00, which is consistent with the measurement time. In addition to collecting basic information and lighting attributes, the questionnaire also displays a guide map of the route and survey points (Figure 10), and automatically obtains the real geographical coordinates of the current location and returns them to the background when each survey point is submitted. In order to further ensure the validity of the questionnaire, the applet also sets a buffer range of $20 \mathrm{~m}$, that is, when the error between the real-time point and the coordinate point in the system is less than $20 \mathrm{~m}$, the submission can be successful; otherwise, the submission cannot be completed.

\subsection{Data Management and Statistics Method}

Through the questionnaire survey mini program, we can get the actual feeling data of the public for the light environment at night. Small program background data using JSON file format, easy to read and parse.

The basic information of the questionnaire survey is shown in Table 1. 
调查点: 点1-1(1/16) Survey Points: Point1-1 (1/16)

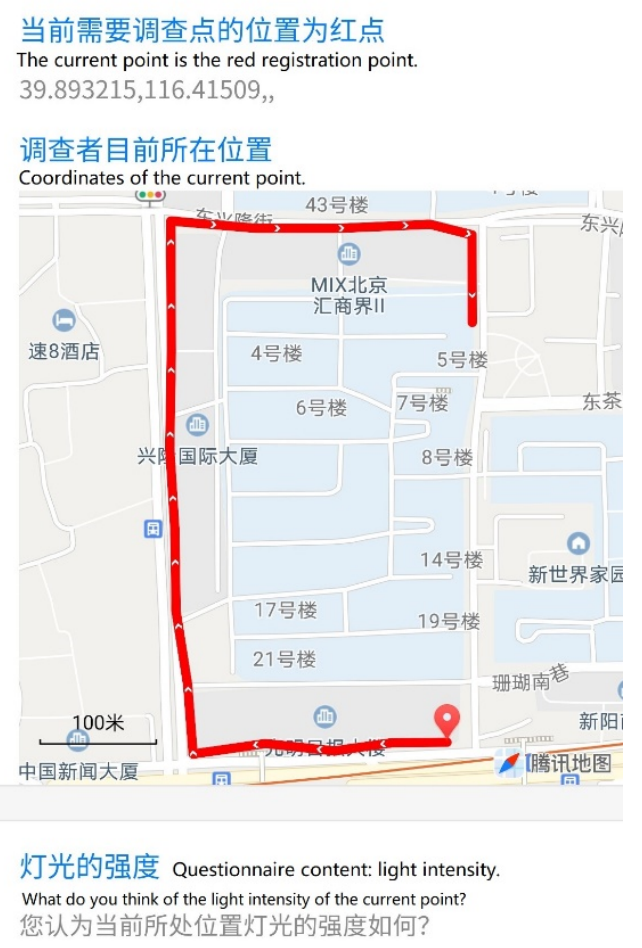

Figure 10. Guide map of routes and survey points in the applet interface (Because the applet is used in Wechat applications in China, the built-in map and questionnaire are in Chinese).

Table 1. Statistics of basic information of the questionnaire.

\begin{tabular}{cccc}
\hline Items & Category & Frequency & Percentage \\
\hline \multirow{2}{*}{ Gender } & Male & 51 & 54.3 \\
& Female & 43 & 45.7 \\
\hline \multirow{3}{*}{ Education } & Doctor & 20 & 21.3 \\
& Master & 54 & 57.4 \\
& Bachelor & 11 & 11.7 \\
& Junior College & 1 & 1.1 \\
& High School or Below & 8 & 8.5 \\
\hline \multirow{2}{*}{ Age } & $18-30$ & 68 & 72.3 \\
& $31-40$ & 12 & 12.8 \\
& $41-50$ & 6 & 6.4 \\
& Oover 51 & 8 & 8.5 \\
\hline & & 94 & 100.0 \\
\hline
\end{tabular}

Table 1 shows the results of the survey data obtained by 22 March 2021, including a total of 1627 reports from 94 respondents at 65 survey sites in 4 study residential areas. Among them, Jinrongjie street 25 copies, Chongwenmenwai street 21 copies, Chunshu street 24 copies, Beitaipingzhuang street 24 copies. Among the respondents, $54.3 \%$ are male, $45.7 \%$ are female, $57.4 \%$ have master's degree, $21.3 \%$ have doctor's degree, and $72.3 \%$ are between 18 and 30 years old.

Each participant will also evaluate the overall feeling of security (0-very unsafe; 1-feeling a little insecure; 2-feel a little safe; 3-feeling very safe) and overall feeling of comfort ( 0 -feeling very uncomfortable; 1 -feeling a little uncomfortable; 2 -feel a little comfortable; 3 -feel very comfortable) of the walking route. The survey mean values are 
shown in Table 2. A score greater than 1.5 indicates a preference for security, while a score less than 1.5 indicates a preference for unsafe. According to the statistics, Chongwenmenwai street outside the average score of security is 2.18 , is the safest of the four routes; The average score for the sense of security of Jinrongjie Street was 2.15 , second only to Chongwenmenwai street. The average score of the sense of security was 1.36 , slightly inclined to unsafe; With an average security score of 1.07 , the Chunshu street route made residents feel the least safe of the four routes.

Table 2. The evaluation of influence of route lighting attributes on comfort and security.

\begin{tabular}{cccccc}
\hline \multicolumn{2}{c}{ Items } & Chongwenmenwai & Jinrongjie Street & Beitaipingzhuang & Chunshu \\
\hline \multicolumn{2}{c}{ Total feeling of security } & 2.18 & 2.15 & 1.36 & 1.07 \\
\hline \multirow{2}{*}{$\begin{array}{c}\text { Influence degree of } \\
\text { parameter to }\end{array}$} & Light Intensity & 1.95 & 2.08 & 2.00 & 2.11 \\
feelings of comfort & Color temperature & 1.45 & 1.08 & 1.24 & 1.22 \\
& Gniform & 1.77 & 1.50 & 1.48 & 1.24 \\
Influence degree of & Light Intensity & 1.41 & 1.31 & 2.28 & 1.41 \\
parameter to & Color temperature & 1.27 & 2.32 & 1.28 & 2.30 \\
feelings of security & Uniform & 1.73 & 1.58 & 1.56 & 1.11 \\
& Glare & 1.00 & 1.15 & 1.16 & 1.70 \\
\hline
\end{tabular}

Residents feel more secure and comfortable on the Chongwenmenwai street with high red light and Jinrongjie street with high blue light. In Beitaipingzhuang street with low blue light and Chunshu street with low red light, residents believe that the light intensity can most affect the feeling of security and feeling of comfort. Whereas residents in Jinrongjie street and Chongwenmenwai street believe that the uniformity of lighting affects residents' feeling of security and comfort to a great extent. This indicates that in areas with sufficient lighting, residents' need for light intensity to assess comfort naturally decreases, while in areas with insufficient lighting, residents' sense of security and comfort largely depends on the intensity of light. Table 2 also showed that glare index (glare) was negatively correlated with residents' feelings of security and comfort when there was plenty of light, while the negative correlation was weaker when there was insufficient light.

Statistical analysis was carried out on 6 attributes of each respondent on each survey route at each survey point, and then the gender, age and education level of the respondent were obtained according to the unique identification code of the respondent. Corresponding statistics and calculations are also required for the background results obtained by using the applet.

The following results need to be calculated for the questionnaire:

1. Total score of 6 attributes of each survey points on each route (consistent with the number of survey points on this route).

2. The sum of illuminance scores, color temperature scores, uniformity scores, glare scores, safety scores, and comfort scores (six items) of all survey points on the route for each respondent. These are used to evaluate the overall route.

3. The average value of all the respondents' evaluation of each light attribute of each survey point. (The number is calculated as the number of points of this route multiplied by 6).

The above survey and measurement results will be used as important parameters for constructing the public space lighting comfort evaluation model.

\section{Experiments and Results}

\subsection{Structural Equation Model}

In the field of social science research, there are many concepts that cannot be directly measured and observed. For example, the comfort level concerned in this paper is an abstract concept. As a latent variable that is difficult to measure directly and accurately, 
comfort level can only be expressed indirectly by some explicit indicators. Traditional statistical methods cannot deal with the latent variable of comfort effectively, while structural equation modeling (SEM) can deal with both latent variable and index. SEM also has the function of verification, processing complex theoretical patterns, and making appropriate evaluation of theoretical patterns according to the consistency of the relationship between patterns and data $[36,37]$.

Observable variable refers to variables that can be directly observed or measured, such as illumination and color temperature. A latent variable, as opposed to an observable variable, is one that is not directly observed but is inferred (through a mathematical model) from other observable variables. The latent variable is the comprehensive reaction of more than two observable variables. In turn, the latent variable can also explain the change of the value of the observable variable to a certain extent. An explanatory model consisting of latent variables and observable variables is called a measurement model.

Structural model studies the linear regression equation between variables (including latent variables and observable variables). The more interleaved the relationship between variables, the more linear the regression equation [38].

Structural equation model analysis has the following advantages [36,39-43]: (1) structural equation model analysis can simultaneously consider and process multiple dependent variables; (2) structural equation model analysis allows independent variables and dependent variables to contain measurement errors; (3) the factor structure and factor relationship can be estimated at the same time; (4) measurement models that allow greater flexibility; (5) it can estimate the degree of fit of the entire model to determine which model is closer to the relationship presented by the data.

SEM was used to evaluate the overall comfort of the route, and the comfort evaluation model was built. The basic procedure of structural equation model analysis is in Figure 11. Based on the above, SEM was used to evaluate the overall comfort of the route, and the comfort evaluation model was built.

\subsection{Comfort Evaluation Model Results}

Mplus software was used for structural equation model analysis in this research. Since the Mplus software for structural equation model analysis lacks the ability of data management, it needs to be processed in SPSS (SEM1109.sav in Supplementary Materials) [44].

In this paper, SPSS software was used to conduct descriptive statistical analysis and normal distribution test on the survey report results of lighting attributes filled in by respondents from 65 assessment points in 4 residential areas and the field measurement data collected by the researchers.

In the questionnaire, a Likert four-point scale was used, and the value of each light attribute variable was between 0 and 3 points. All factors should be standardized to represent the relative importance between observable variables and latent variables. Since different variables and indicators have different dimensions and dimensional units, which will affect the results of data analysis, in order to eliminate the impact and meet the application conditions of structural equation model, the min-max standardization method was used to standardize the data of each variable to 0 3 (Equation (5)).

$$
x^{*}=3 \times \frac{x}{\max },
$$

where, $x^{*}$ represents the result after standardization, and $x$ represents the original data; $\max$ represents the maximum value of all data of this item. Through the standardized formula, the field measurement data and questionnaire data are unified. 


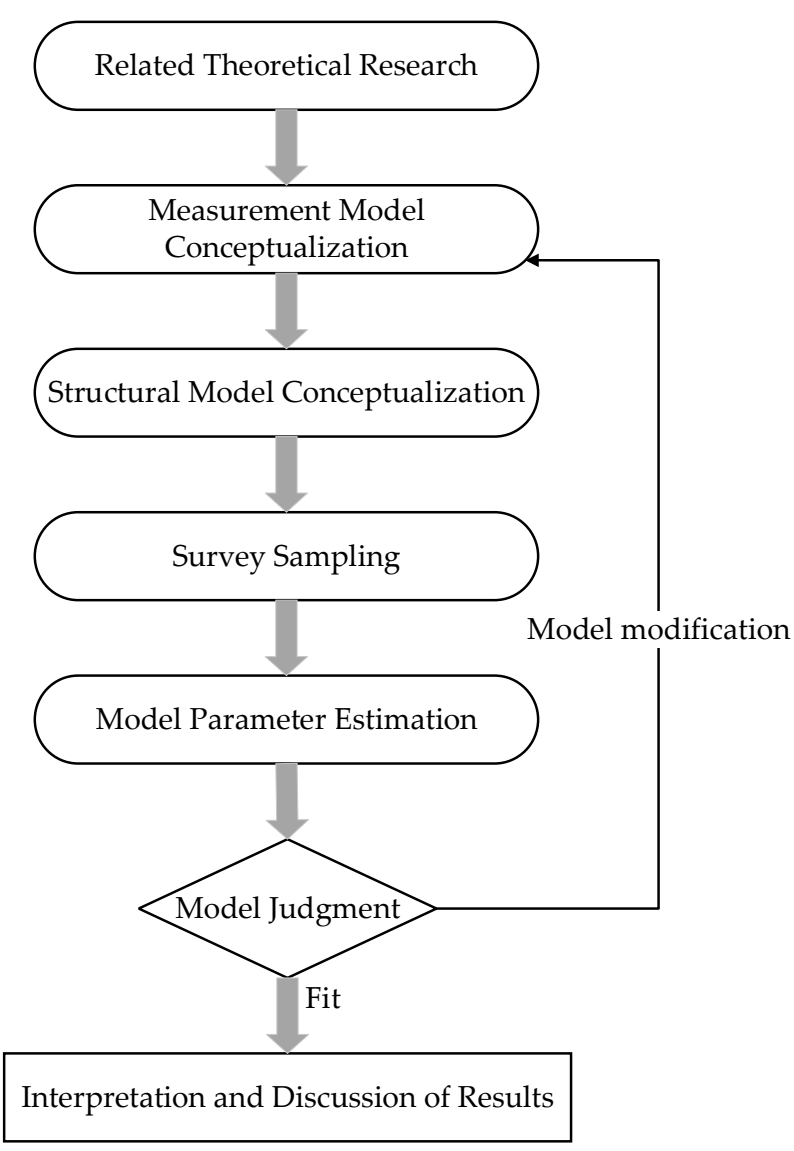

Figure 11. Structural equation model analysis of the basic procedures.

The hypothetical structural equation model diagram shown in Figure 12 includes measurement model and structural model, in which uniformity and color temperature (temperature in Figure 12) are exogenous latent variables, security and comfort are endogenous latent variables, Un1, Un2, Uni, S1-S3, Sec, T1, T2, Tem, C1, C2 and Com are all observable variables, and e1-e21 are variable residuals (unexplainable variables). Un1 is the standard deviation of the illuminance in the eight directions; Un2 is the ratio of the minimum to the maximum illuminance in the eight directions; Uni is the mean value of the respondents' score on the brightness uniformity of the evaluation point. S1 represents the mean value of measured illuminance; S2 represents the measured value of glare index; S3 represents the number of lamps illuminated at the evaluation point; Sec is the mean value of respondents' security score at the evaluation point. T1 represents the mean value of x-color temperature measurement of the light at the measuring point; $\mathrm{T} 2$ represents the mean value of $y$-color temperature measurement of the light at the measuring point; Tem is the mean color temperature score value of the respondents at the evaluation point. $\mathrm{C} 1$ represents the mean illuminance score of the respondents at the evaluation point; $\mathrm{C} 2$ represents the mean glare index score of the respondents at the evaluation point; Com represents the mean overall feeling of comfort score of the respondents at the evaluation point.

The probability of significant confirmatory analysis of structural equation model analysis is relatively low. The analysis needs to assume and draw the structural equation model in advance, and then verify it through the questionnaire data, and fit the structural equation model before it can be considered that the hypothesis holds. The key to the establishment of this model depends largely on the structure of the initial hypothetical model. Figure 13 is the syntax of structural equation model construction in Mplus software based on the hypothetical model. 


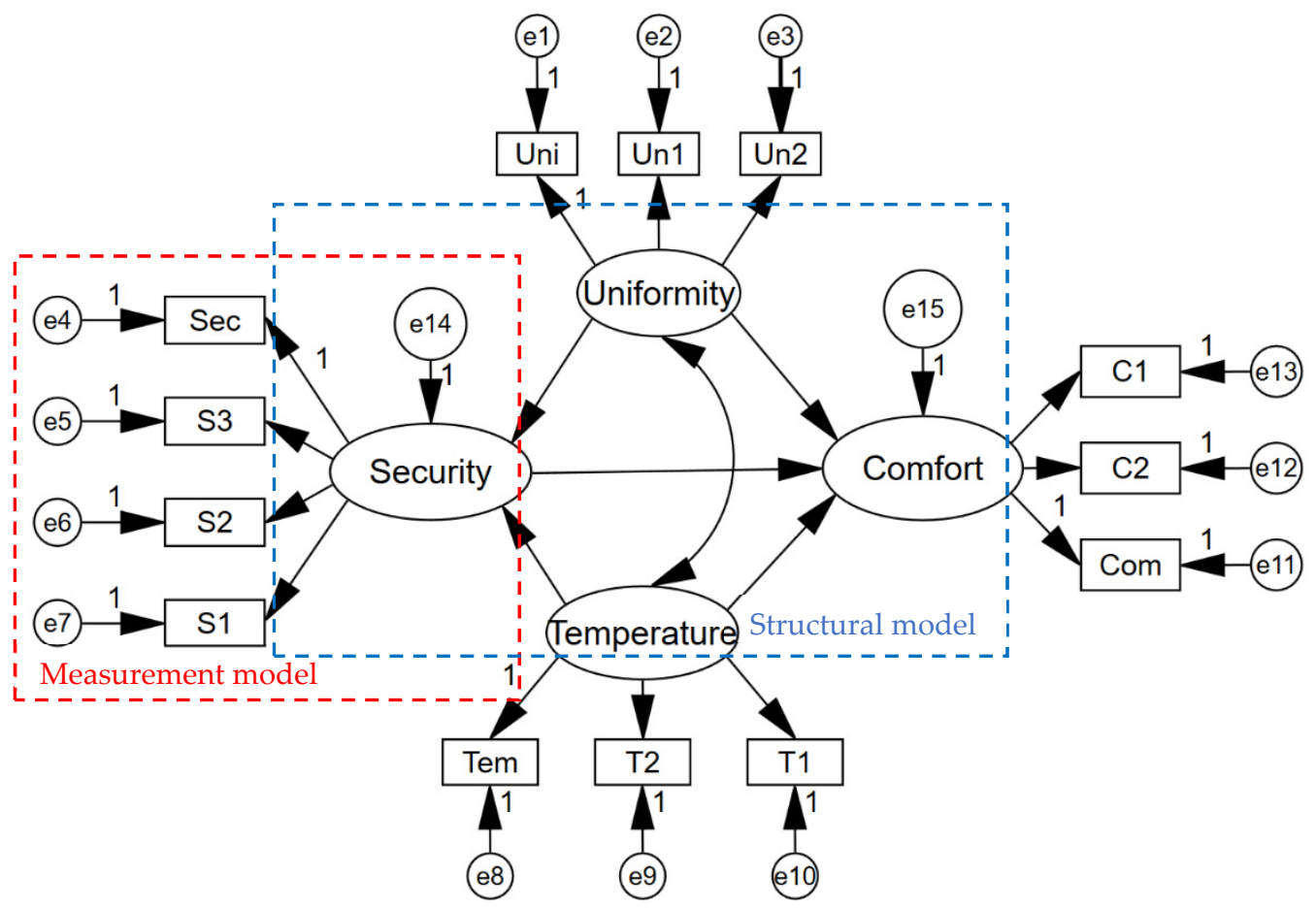

Figure 12. This research uses prior knowledge to assume a structural equation model.

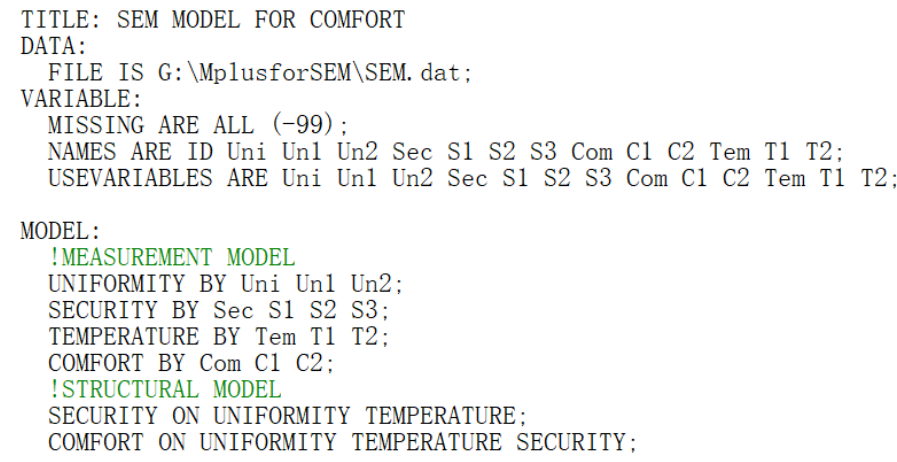

Figure 13. Construction of structural equation model in Mplus software based on the hypothetical model.

Because this study uses the questionnaire data, the observed Likert scale is a four-point scale, and the field measurement data are also standardized to a four-point scale. In the process of model construction, if the observed Likert scale is less than the five-point scale data, Mplus software will use the WLSMV (weight least square with mean and variance) estimation method for conversion and estimation, and whether it is significant can be read through the schematic diagram of the results.

The model results (Figure 14 and Table 3) show that there are 19 continuous dependent variables and 4 continuous latent variables (comfort1-20220104.inp in Supplementary Materials). Uniformity and temperature (color temperature) are exogenous latent variables, and security and comfort are endogenous latent variables. BY in Table 3 represents the measurement model, ON represents the structural model, and WITH represents the relationship between the exogenous latent variables. 


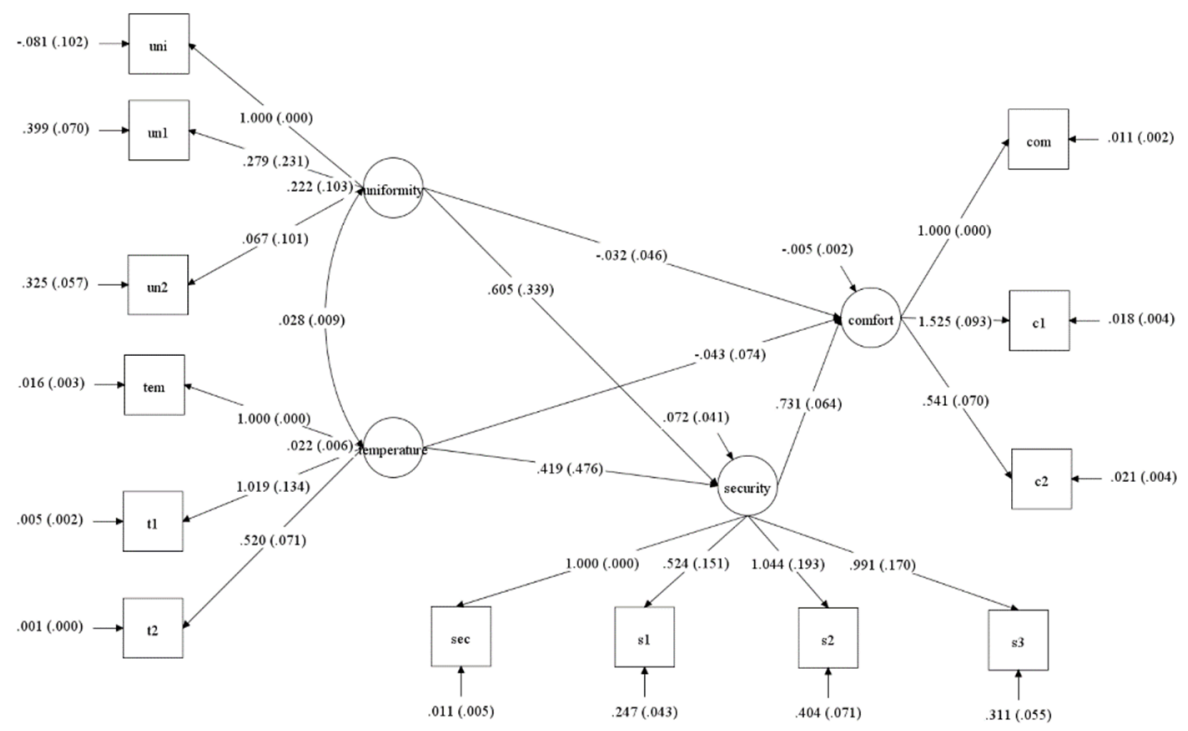

Figure 14. Run results of the comfort evaluation model.

Table 3. The results of the hypothetical comfort evaluation model.

\begin{tabular}{|c|c|c|c|c|}
\hline & Estimate & Standard Error (S.E.) & Est./S.E. & $p$-Value \\
\hline \multicolumn{5}{|l|}{ Uniformity BY } \\
\hline Uni & 1.000 & 0.000 & 999.000 & 999.000 \\
\hline Un1 & 0.279 & 0.231 & 1.207 & 0.227 \\
\hline Un2 & 0.067 & 0.101 & 0.662 & 0.508 \\
\hline \multicolumn{5}{|l|}{ Security BY } \\
\hline Sec & 1.000 & 0.000 & 999.000 & 999.000 \\
\hline $\mathrm{S} 1$ & 0.524 & 0.151 & 3.473 & 0.001 \\
\hline S2 & 1.044 & 0.193 & 5.405 & 0.000 \\
\hline S3 & 0.991 & 0.170 & 5.822 & 0.000 \\
\hline \multicolumn{5}{|l|}{ Temperature BY } \\
\hline Tem & 1.000 & 0.000 & 999.000 & 999.000 \\
\hline $\mathrm{T} 1$ & 1.019 & 0.134 & 7.577 & 0.000 \\
\hline $\mathrm{T} 2$ & 0.520 & 0.071 & 7.350 & 0.000 \\
\hline \multicolumn{5}{|l|}{ Comfort BY } \\
\hline Com & 1.000 & 0.000 & 999.000 & 999.000 \\
\hline C1 & 1.525 & 0.093 & 16.477 & 0.000 \\
\hline $\mathrm{C} 2$ & 0.541 & 0.070 & 7.772 & 0.000 \\
\hline \multicolumn{5}{|l|}{ Security ON } \\
\hline Uniformity & 0.605 & 0.339 & 1.785 & 0.074 \\
\hline Temperature & 0.419 & 0.476 & 0.881 & 0.379 \\
\hline \multicolumn{5}{|l|}{ Comfort ON } \\
\hline Uniformity & -0.032 & 0.046 & -0.693 & 0.489 \\
\hline Temperature & -0.043 & 0.074 & -0.576 & 0.565 \\
\hline Security & 0.731 & 0.064 & 11.385 & 0.000 \\
\hline \multicolumn{5}{|l|}{ Temperature } \\
\hline Uniformity & 0.028 & 0.009 & 3.190 & 0.001 \\
\hline
\end{tabular}

Table 3 shows that the absolute values of signal-to-noise ratio (=Est./S.E. in Table 3) on Un1 and Un2 are so low that the two variables do not significantly contribute to the model results. In addition, the evaluation weights of Un1 and Un2 directions are too small, and the P-values are greater than 0.05 , indicating that these two factors should be removed. 
It can also be seen from the results that uniformity and temperature were not suitable for directly acting on comfort, so the model needed to be modified.

The model also shows that the influence of endogenous potential variables of security is less affected by uniformity and color temperature. The evaluation of comfort mainly depends on the variable of security, and the influence of uniformity and color temperature can be ignored. At the same time, there is correlation between color temperature and uniformity.

The model is adjusted according to the hypothetical model result until the best fitting model result is obtained. The best fitting results were obtained after several revisions of the model (Figure 15) (adjust4.inp in Supplementary Materials).

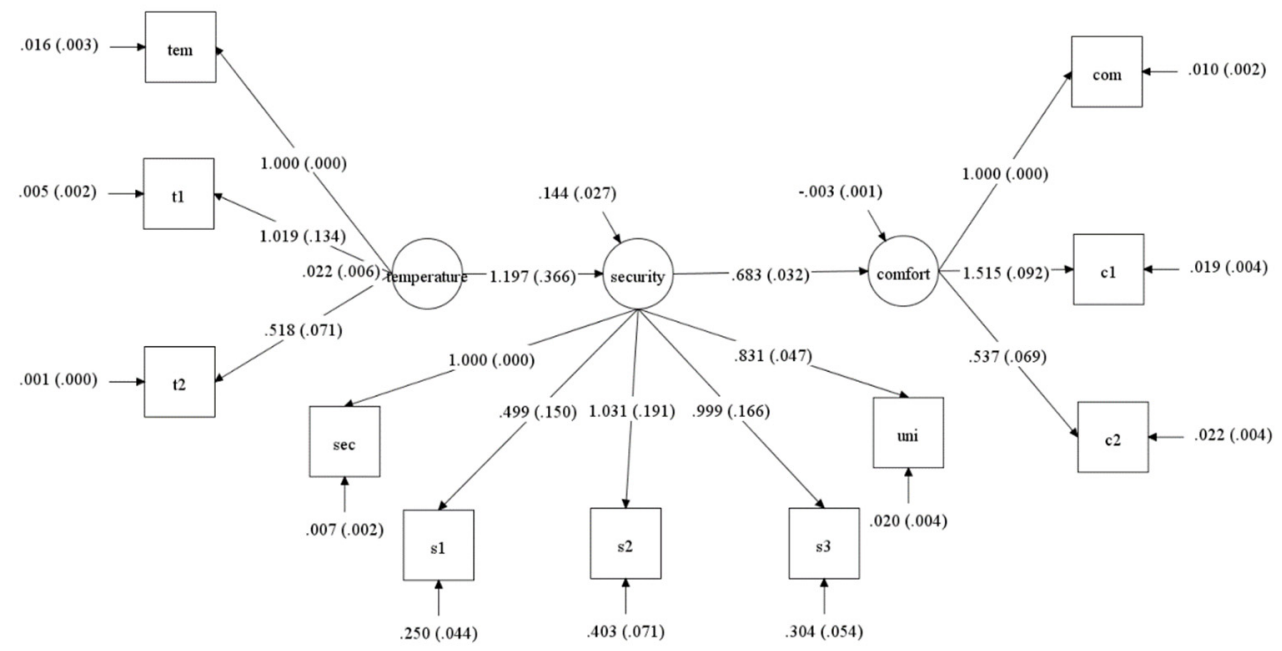

Figure 15. Comfort evaluation model of public space lighting in typical residential areas of Beijing.

The results of the comfort evaluation model can be expressed separately as:

$$
\text { Temperature }=\text { Tem }+1.019 \times T 1+0.518 \times T 2+0.022,
$$

$$
\begin{array}{r}
\text { Security }=S e c+0.499 \times S 1+1.031 \times S 2+0.999 \times S 3+0.831 \times \text { Uni }+1.197 \times \text { Temperature }+0.144, \\
\text { Comfort }=C o m+1.515 \times C 1+0.537 \times C 2+0.683 \times \text { Security }-0.003,
\end{array}
$$

where, parameters are the same as in the model diagram.

The final SEM for comfort is:

$$
\begin{aligned}
\text { Comfort } & =\mathrm{Com}+1.515 \times \mathrm{C} 1+0.537 \times \mathrm{C} 2+0.683 \times[\mathrm{Sec}+0.499 \times S 1+1.031 \times S 2+0.999 \times S 3+ \\
& 0.831 \times U n i+1.197 \times(\mathrm{Tem}+1.019 \times \mathrm{T} 1+0.518 \times \mathrm{T} 2+0.022)+0.144]-0.003,
\end{aligned}
$$

or:

$$
\begin{aligned}
& \text { Comfort }=\mathrm{Com}+1.515 \times C 1+0.537 \times C 2+0.683 \times \mathrm{Sec}+0.341 \times S 1+0.704 \times S 2+0.682 \times S 3 \\
& +0.568 \times U n i+0.818 \times \mathrm{Tem}+0.833 \times \mathrm{T} 1+0.423 \times \mathrm{T} 2+0.108 \text {, }
\end{aligned}
$$

where, parameters are the same as in the model diagram.

According to the sample analysis results of the structural equation model analysis, when the public comfort level cannot be directly obtained, the comfort level of the study area can be obtained through other observable variables and corresponding model parameters.

The results (Figure 15, Table 4 and Equation (10)) show that the feeling of security and the observable variables affect the comfort of residents. Among them, the color temperature affects the feeling of security, and the feeling of security affects the feeling of comfort. Among the parameters of the comfort model results, $\mathrm{C} 1$, sec, and tem have absolute weight advantages in the model. $\mathrm{C} 1$ is the evaluation score of residents on light 
illumination, sec is the evaluation score of residents on feeling of security, and tem is the evaluation score of residents on color temperature. The results show that the residents evaluation results have a great impact on the final comfort model, which shows that the model can reflect the residents' feeling of comfort in the public space lighting environment.

Table 4. The final results of the hypothetical comfort evaluation model.

\begin{tabular}{ccccc}
\hline & Estimate & Standard Error (S.E.) & Est./S.E. & $p$-Value \\
\hline Security BY & & & & \\
Sec & 1.000 & 0.000 & 999.000 & 999.000 \\
S1 & 0.499 & 0.150 & 3.327 & 0.001 \\
S2 & 1.031 & 0.191 & 5.399 & 0.000 \\
S3 & 0.999 & 0.166 & 6.021 & 0.000 \\
Uni & 0.831 & 0.047 & 17.672 & 0.000 \\
\hline Temperature BY & & & & \\
Tem & 1.000 & 0.000 & 999.000 & 999.000 \\
T1 & 1.019 & 0.134 & 7.582 & 0.000 \\
T2 & 0.518 & 0.071 & 7.327 & 0.000 \\
\hline Comfort BY & & & & \\
Com & 1.000 & 0.000 & 999.000 & 999.000 \\
C1 & 1.515 & 0.092 & 76.512 & 0.000 \\
C2 & 0.537 & 0.069 & 7.750 & 0.000 \\
\hline Security ON & & & 3.265 & 0.001 \\
Temperature & 1.197 & 0.366 & & \\
\hline Comfort ON & & & 21.372 & 0.000 \\
Security & 0.683 & 0.032 &
\end{tabular}

Based on the results of comfort model, the public space lighting comfort of four typical residential areas was calculated, respectively (Figure 16).

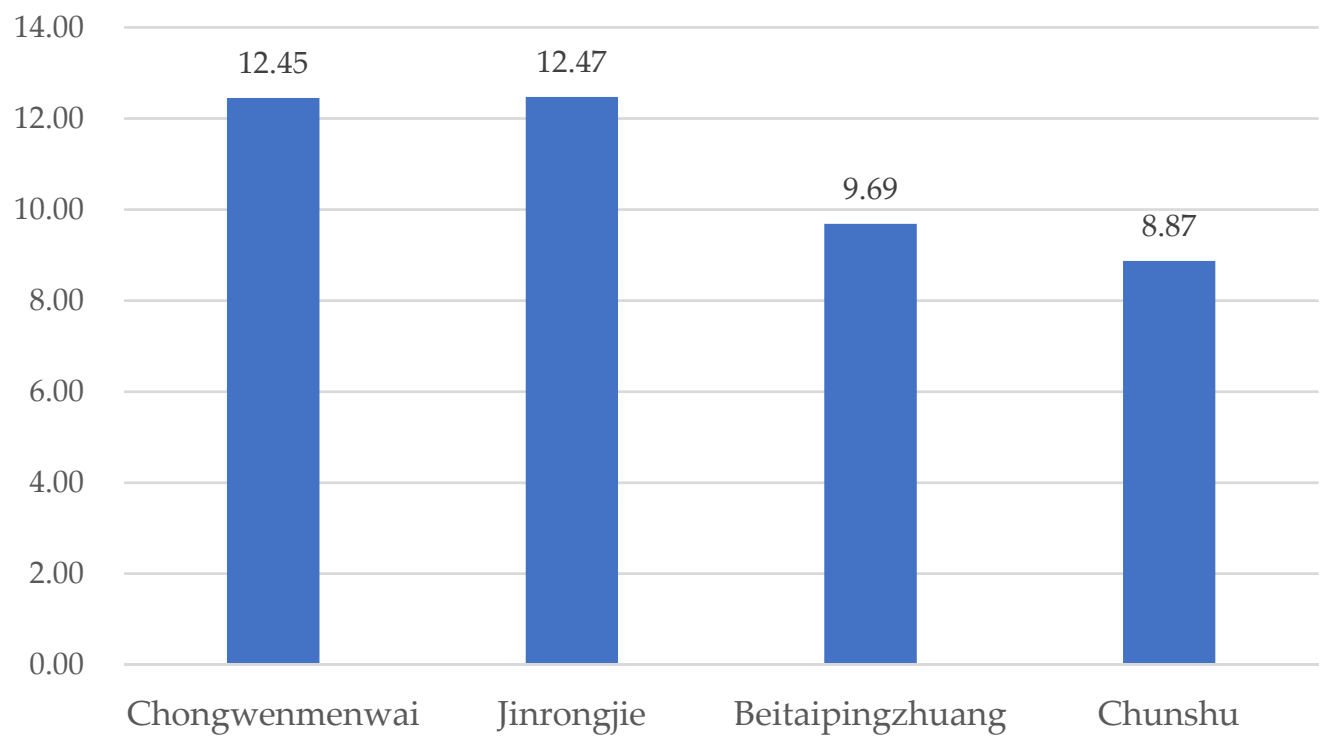

Figure 16. The public space lighting comfort results of four typical residential areas.

It can be seen from the comfort results of four typical residential areas that Chongwenmenwai street and Jinrongjie street are more comfortable than Beitaipingzhuang street and Chunshu street, indicating that the areas with high light intensity are more comfortable than the areas with low light intensity.

In order to further explore the feedback of the luminous remote sensing data from the measured lighting data of the four routes and the public perception survey data, this paper 
used a multi-factor analysis method to evaluate the lighting score on each route separately. The selected factors were illuminance $\left(E_{\mathrm{V}}\right)$ in the measurement data, $x$ color temperature $(\mathrm{x})$, y color temperature $(\mathrm{y})$, glare index and the six items of public perception survey data. The six items are illumination, color temperature, uniformity, glare perception, feeling of security, feeling of comfort.

The data used passed the KMO (Kaiser-Meyer-Olkin) and Bartlett significance test, and then the variance of the original variables explained by each component in the principal component analysis was used to determine the number of common factors, and the factors with a large cumulative variance contribution rate were retained (Table 5).

Table 5. The variance contribution rate of each street route component.

\begin{tabular}{cccc}
\hline \multirow{2}{*}{ Route } & \multicolumn{3}{c}{ Component Variance Contribution Rate } \\
\cline { 2 - 4 } & $\mathbf{1}$ & $\mathbf{2}$ & $\mathbf{3}$ \\
\hline Chongwenmenwai street & 49.135 & 34.520 & - \\
Jinrongjie street & 44.646 & 23.091 & 18.841 \\
Beitaipingzhuang street & 40.074 & 29.451 & 16.590 \\
Chunshu street & 42.470 & 27.287 & 13.527 \\
\hline
\end{tabular}

The component score coefficient matrix was obtained to express the relationship between each index variable and the extracted common factors (Table 6). If the score on a common factor is higher, it means that the relationship between the index and the common factor is closer.

Through the interpretation of Tables 5 and 6, the following results can be drawn:

(a) The nighttime light image reflects that Chongwenmenwai street has high red light. The light information of this route is mainly concentrated on the first principal component. In its public space lighting evaluation score, the larger weight is the illumination perception, uniformity perception, security and comfort in the public perception data, and the weights of these four perception variables are almost the same. The second is glare index and glare perception, and the smallest weight is color temperature. This shows that in an area with high light intensity, people's perception of the public space lighting environment is the main part of the lighting evaluation in this area. People pay more attention to the feeling brought by the lighting environment in this area, but they pay less attention to whether the color temperature is mild or not. This shows that the comprehensive lighting conditions in this area are relatively good, the light is relatively uniform, and people have a good feeling of security and comfort.

(b) The nighttime light remote sensing image reflects that the blue light intensity of Jinrongjie street is very high. The lighting comprehensive evaluation score of the route in this area is composed of three principal components. Among them, the weight of glare perception and glare index is the largest, indicating that the residents have a high degree of feedback on the dazzling degree of the route in this area, which greatly affects the comprehensive score of this area. However, due to the high intensity of blue light, the glare index and glare perception greatly affect the lighting evaluation of the route. The color temperature is still the lowest in the comprehensive score of this area.

(c) The nighttime light image reflects that Beitaipingzhuang street has low blue light. Due to the lack of light, residents pay high attention to the color temperature, which shows that the degree of cold and warm is the key to the comprehensive lighting score of the area where the lighting is insufficient, and the change of color temperature is particularly prominent in this case. Moreover, the weights of feeling of comfort and security are reduced relatively. This shows that in an area with low light, people need more basic lighting than security and comfort. In this case, residents pay more attention to whether the public space lighting can meet the normal lighting needs of pedestrians. 
Table 6. The score coefficient matrix of each route component.

\begin{tabular}{|c|c|c|c|c|c|c|c|c|c|c|c|c|}
\hline \multicolumn{2}{|c|}{ Items } & \multicolumn{2}{|c|}{ Chongwenmenwai } & \multicolumn{3}{|c|}{ Jinrongjie Street } & \multicolumn{3}{|c|}{ Beitaipingzhuang } & \multicolumn{3}{|c|}{ Chunshu } \\
\hline & & 1 & 2 & 1 & 2 & 3 & 1 & 2 & 3 & 1 & 2 & 3 \\
\hline \multirow{4}{*}{ Measurement data } & $\mathrm{E}_{\mathrm{v}}$ & 0.118 & -0.267 & -0.053 & -0.097 & 0.486 & 0.147 & -0.451 & 0.236 & 0.004 & -0.197 & 0.508 \\
\hline & $x$ & -0.020 & 0.287 & -0.152 & 0.460 & 0.077 & -0.123 & 0.339 & 0.131 & -0.082 & 0.356 & 0.087 \\
\hline & $\mathrm{y}$ & -0.005 & 0.276 & 0.115 & 0.308 & -0.204 & -0.062 & 0.290 & 0.133 & 0.010 & 0.314 & -0.098 \\
\hline & glare index & 0.156 & 0.022 & -0.214 & 0.001 & 0.679 & 0.044 & -0.135 & 0.620 & -0.117 & 0.115 & 0.679 \\
\hline \multirow{6}{*}{$\begin{array}{l}\text { Public perception } \\
\text { survey data }\end{array}$} & Illumination & 0.199 & -0.034 & 0.179 & 0.002 & 0.046 & 0.229 & -0.013 & -0.032 & 0.208 & -0.041 & 0.105 \\
\hline & Color temperature & 0.031 & 0.250 & -0.037 & 0.381 & -0.031 & 0.302 & -0.256 & 0.258 & 0.003 & 0.296 & 0.086 \\
\hline & Uniformity & 0.201 & -0.028 & 0.226 & -0.007 & -0.072 & 0.260 & -0.095 & 0.103 & 0.223 & 0.065 & -0.173 \\
\hline & Glare perception & 0.123 & 0.045 & 0.320 & -0.110 & -0.238 & 0.214 & -0.120 & -0.276 & 0.237 & -0.080 & -0.157 \\
\hline & Feeling of security & 0.201 & -0.024 & 0.207 & -0.035 & -0.002 & 0.152 & 0.116 & -0.138 & 0.232 & -0.031 & 0.013 \\
\hline & Feeling of comfort & 0.197 & -0.081 & 0.192 & 0.052 & -0.022 & 0.182 & 0.074 & -0.157 & 0.207 & 0.022 & 0.005 \\
\hline
\end{tabular}


(d) The nighttime light image reflects that Chunshu street has low red light. The weights of glare index and glare perception are relatively high in this route. Followed by the weights of illumination, uniformity, security and comfort. This shows that the illumination degree of this area is not bad. However, people can feel a certain degree of glare. Therefore, on the basis of meeting the basic lighting conditions, the glare problem in this area should be solved first.

Through the analysis, it can be concluded that the performance of the lighting phenomenon reflected by each typical residential area is consistent with that reflected by the luminous remote sensing image within the allowable error range. When people live in the outdoor public space light environment with good lighting conditions, they will pay more attention to the feelings of light uniformity, comfort and security. Whereas when people live in the outdoor public space light environment with poor lighting conditions, the feelings of color temperature and glare are more obvious. In addition, the blue light radiation in the area corresponding to the dazzling glare is obvious. The blue light with short wavelength not only makes people feel visual discomfort, but also does great harm to people's physical and mental health. From the above concerns, we can further discuss the impact of blue light pollution in the future research.

\section{Discussion}

With the development of economy and the improvement of people's living standards, the quantity of lighting is no longer the main factor restricting the quality of life, and the quality of lighting is the new pursuit point. A comfortable and reasonable night lighting environment not only reduces people's mental stress visually, but also has important significance for the construction of smart cities and the sustainable development of society. Nighttime light remote sensing, as a special existence in the field of remote sensing, can provide technical support for statistical economic and social dynamic development and assessment of socio-economic issues. Therefore, starting from the public's perception of the comfort of public space lighting, this paper used the acquired high-resolution nighttime light remote sensing data (ISS and Jilin-1) and field measurement instruments (CL-500A and LS-160) to measure the survey points of four typical residential areas on different routes.

Structural equation model and multi-factor analysis method were used to express the residents' feeling of comfort in public space light environment using field measurement factors and survey factors. The results of the model can reflect people's preference for lighting properties of public space lighting. The areas with high light intensity are more comfortable than the areas with low light intensity. People are most sensitive to light illuminance (intensity) in the lighting environment of public spaces, and the illuminance greatly affects people's perception of the comfort of space lighting. In areas with high light intensity, people pay more attention to the uniformity, security and comfort of the light, while in areas with low light intensity or high blue light, people's perception of glare will be more obvious. Moreover, the results of comfort evaluation model construction will vary according to different pre-assumed models.

Therefore, in the public space lighting optimization, on the basis of ensuring light intensity, we should invest in warm color lamps with little harm to human health and lamps with low energy consumption. From the perspective of urban residents' public space lighting, the following guiding suggestions can be provided for municipal lighting planning:

1. Strengthen the collection and management of intelligent information based on the construction of smart city;

2. From the perspective of sustainable development, reduce the blue light pollution in the public space lighting, so as to reduce the harm to human health;

3. In terms of energy allocation, lighting energy shall be reasonably distributed according to the characteristics of different residential areas to promote sustainable economic development.

This research also has the following limitations: 
1. Due to the impact of the COVID-19 pneumonia epidemic, the survey questionnaires for collecting public perception data in this research are limited, which may have an impact on the results of the comfort evaluation model.

2. The time of image acquisition is inconsistent with the time of field survey and measurement, which makes the quantitative study of nighttime light data difficult.

3. The results of this study are limited, and application to other cities, such as cities with lower population densities and GDP levels, requires more experimental studies.

This paper also comes to the conclusion that more light is better, but from the perspective of social humanities, the increase in light does not necessarily improve the feelings of security and comfort of pedestrians, especially for different groups and walking places. Moreover, people's perception of the outdoor light environment of public space lighting may be affected by more factors such as seasons, tree occlusion, and traffic flow. In the future, more factors can be considered to comprehensively evaluate public space lighting.

\section{Conclusions}

This paper established a set of public space lighting evaluation method that integrate public perception, nighttime light remote sensing data and field measurement data. The research combined the red and blue light intensity of nighttime light remote sensing image and socio-economic parameters, and then used the instrument to measure the light attributes of the survey points on the measurement route the intelligent WeChat applet was used to collect the residents' perception of each survey point, and to constitute the light attribute sample database of each measurement route. The structural equation model analysis method was used to construct the urban residents' public space lighting comfort evaluation model, and from the model results, the lighting attributes that affect the comfort of residents were analyzed. The research results not only reflect the residents' preference for urban public space lighting, but also combine the three elements of space, ground and man, to provide a basis for the development of nighttime light quantitative research, and to provide support for the construction of smart cities and the sustainable development of social economy.

Supplementary Materials: The following supporting information can be downloaded at: https: //www.mdpi.com/article/10.3390/rs14030655/s1, the data presented in this study.

Author Contributions: Conceptualization, W.J. and S.W.; methodology, S.W., H.L. and T.L.; formal analysis, S.W.; investigation, W.J., S.W., H.L., Y.L. and T.L.; data curation, S.W. and Y.L.; writingoriginal draft preparation, S.W.; writing-review and editing, S.W., W.J., P.J., R.H., Y.X. and N.Z.; project administration, W.J.; funding acquisition, W.J., T.L., P.J. and Y.X. All authors have read and agreed to the published version of the manuscript.

Funding: This research was funded by the National Key Research and Development Programs of China (grant number 2017YFE0125900, grant number 2017YFC0506502), key project of president's Fund of Chinese Academy of Forestry (grant number CAFYBB2020ZB007-1), the program of the National Natural Science Foundation of China (grant number 61731022), and National Science Foundation for Young Scientists of China (grant number 61701495).

Data Availability Statement: The data presented in this study are available in Supplementary Material.

Acknowledgments: We would like to thank all the respondents who participated in the field survey. We would like to thank the providers of ISS image (https: / / eol.jsc.nasa.gov (access from November 2019 to April 2021)) and Jilin-1 nighttime light remote sensing data (https:/ / mall.charmingglobe.com (access on 10 September 2020)). In particular, we would like to thank Boris A. Portnov and Tamar Trop of University of Haifa in Israel and Ming Liu of Dalian University of technology for their support in the typical residential areas' selection method, lighting measurement and investigation methods.

Conflicts of Interest: The authors declare no conflict of interest. 


\section{References}

1. García-Fuentes, M.Á.; Antolín, J.; de Torre, C.; Pérez, A.; Tomé, I.; Mirantes, M.L.; López, F.; Martín, J.; Gómez, J. Evaluation of Results of City Sustainable Transformation Projects in the Fields of Mobility and Energy Efficiency with Real Application in a District in Valladolid (Spain). Sustainability 2021, 13, 9683. [CrossRef]

2. Parent, M.E.; El-Zein, M.; Rousseau, M.C.; Pintos, J.; Siemiatycki, J. Night work and the risk of cancer among men. Am. J. Epidemiol. 2012, 176, 751-759. [CrossRef] [PubMed]

3. Kloog, I.; Haim, A.; Stevens, R.G.; Barchana, M.; Portnov, B.A. Light at Night Co-distributes with Incident Breast but not Lung Cancer in the Female Population of Israel. Chronobiol. Int. 2008, 25, 65-81. [CrossRef]

4. Bauer, S.E.; Wagner, S.E.; Burch, J.; Bayakly, R.; Vena, J.E. A case-referent study: Light at night and breast cancer risk in Georgia. Int. J. Health Geogr. 2013, 12, 23. [CrossRef] [PubMed]

5. Rybnikova, N.; Portnov, B.A. Population-level study links short-wavelength nighttime illumination with breast cancer incidence in a major metropolitan area. Chronobiol. Int. 2018, 35, 1198-1208. [CrossRef] [PubMed]

6. Peña-García, A.; Hurtado, A.; Aguilar-Luzón, M.C. Impact of public lighting on pedestrians' perception of safety and well-being. Saf. Sci. 2015, 78, 142-148. [CrossRef]

7. Liu, M.; Liu, Y.; Liu, Y.; Jiao, W.; Liu, X.; Liu, H. Safety Percection Evaluation and Simulation Optimization of Road Lighting in Residentiai Areas. Zhaoming Gongcheng Xueba 2021, 32, 106-111, 152.

8. Portnov, B.A.; Saad, R.; Trop, T.; Kliger, D.; Svechkina, A. Linking nighttime outdoor lighting attributes to pedestrians' feeling of safety: An interactive survey approach. PLoS ONE 2020, 15, e0242172. [CrossRef]

9. Levin, N.; Kyba, C.C.M.; Zhang, Q.; Sánchez de Miguel, A.; Román, M.O.; Li, X.; Portnov, B.A.; Molthan, A.L.; Jechow, A.; Miller, S.D.; et al. Remote sensing of night lights: A review and an outlook for the future. Remote Sens. Environ. 2020, $237,111443$. [CrossRef]

10. Zhao, M.; Zhou, Y.; Li, X.; Cao, W.; He, C.; Yu, B.; Li, X.; Elvidge, C.D.; Cheng, W.; Zhou, C. Applications of Satellite Remote Sensing of Nighttime Light Observations: Advances, Challenges, and Perspectives. Remote Sens. 2019, 11, 1971. [CrossRef]

11. Elvidge, C.D.; Baugh, K.E.; Kihn, E.A.; Kroehl, H.W.; Davis, E.R.; Davis, C.W. Relation between satellite observed visible-near infrared emissions, population, economic activity and electric power consumption. Int. J. Remote Sens. 1997, 18, 1373-1379. [CrossRef]

12. Forbes, D.J. Multi-scale analysis of the relationship between economic statistics and DMSP-OLS night light images. GISci. Remote Sens. 2013, 50, 483-499. [CrossRef]

13. Li, X.; Li, D. Can night-time light images play a role in evaluating the Syrian Crisis? Int. J. Remote Sens. 2014, 35, 6648-6661. [CrossRef]

14. Yin, R.; He, G.; Jiang, W.; Peng, Y.; Zhang, Z.; Li, M.; Gong, C. Night-time Light Imagery Reveals Chinas City Activity during the COVID-19 Pandemic Period in Early 2020. IEEE J. Sel. Top. Appl. Earth Obs. Remote Sens. 2021, 14, 5111-5122. [CrossRef]

15. Marchant, P. What Works? A Critical Note on the Evaluation of Crime Reduction Initiatives. Crime Prev. Community Saf. 2005, 7, 7-13. [CrossRef]

16. Marchant, P.R. A Demonstration That the Claim That Brighter Lighting Reduces Crime Is Unfounded. Br. J. Criminol. 2004, 44, 441-447. [CrossRef]

17. Steinbach, R.; Perkins, C.; Tompson, L.; Johnson, S.; Armstrong, B.; Green, J.; Grundy, C.; Wilkinson, P.; Edwards, P. The effect of reduced street lighting on road casualties and crime in England and Wales: Controlled interrupted time series analysis. J. Epidemiol. Community Health 2015, 69, 1118-1124. [CrossRef]

18. Chalfin, A.; Kaplan, J.; LaForest, M. Street Light Outages, Public Safety and Crime Attraction. J. Quant. Criminol. 2021, 1-29. [CrossRef]

19. Christopher, N.H.D.; Jan-Peter, M.; Christopher, D.E. Night-time Imagery as a Tool for Global Mapping of Socioeconomic Parameters and Greenhouse Gas Emissions. AMBIO A J. Hum. Environ. 2000, 29, 157-162.

20. Deren, L. Towards the Development of Remote Sensing and GIS in the 21st Century. Geomat. Inf. Sci. Wuhan Univ. 2003, 28, 127-131.

21. Jiang, W.; He, G.; Long, T.; Wang, C.; Ni, Y.; Ma, R. Assessing Light Pollution in China Based on Nighttime Light Imagery. Remote Sens. 2017, 9, 135. [CrossRef]

22. Pauwels, J.; Le Viol, I.; Azam, C.; Valet, N.; Julien, J.F.; Bas, Y.; Lemarchand, C.; Sanchez de Miguel, A.; Kerbiriou, C. Accounting for artificial light impact on bat activity for a biodiversity-friendly urban planning. Landsc. Urban Plan. 2019, 183, 12-25. [CrossRef]

23. Firebaugh, A.; Haynes, K.J. Light pollution may create demographic traps for nocturnal insects. Basic Appl. Ecol. 2019, 34, 118-125. [CrossRef]

24. Jiang, W.; He, G.; Long, T.; Guo, H.; Yin, R.; Leng, W.; Liu, H.; Wang, G. Potentiality of Using Luojia 1-01 Nighttime Light Imagery to Investigate Artificial Light Pollution. Sensors 2018, 18, 2900. [CrossRef] [PubMed]

25. Li, Z.; Zhu, J.; Huang, C. Comparison of Outdoor Light Environment Quality Evaluation Metliods. Zhaoming Gongcheng Xuebao 2018, 29, 113-118.

26. Deng, Y.; Liu, S.; Cai, J.; Lu, X.; Nielsen, C.P. Spatial pattern and its evolution of Chinese provincial population: Methods and empirical study. J. Geogr. Sci. 2015, 25, 1507-1520. [CrossRef]

27. Qi, Y.; Yang, Y.; Jin, F. China's economic development stage and its spatio-temporal evolution: A prefectural-level analysis. J. Geogr. Sci. 2013, 23, 297-314. [CrossRef] 
28. Sánchez de Miguel, A.; Kyba, C.C.M.; Aubé, M.; Zamorano, J.; Cardiel, N.; Tapia, C.; Bennie, J.; Gaston, K.J. Colour remote sensing of the impact of artificial light at night (I): The potential of the International Space Station and other DSLR-based platforms. Remote Sens. Environ. 2019, 224, 92-103. [CrossRef]

29. Sánchez de Miguel, A.; Zamorano, J.; Aubé, M.; Bennie, J.; Gallego, J.; Ocaña, F.; Pettit, D.R.; Stefanov, W.L.; Gaston, K.J. Colour remote sensing of the impact of artificial light at night (II): Calibration of DSLR-based images from the International Space Station. Remote Sens. Environ. 2021, 264, 112611. [CrossRef]

30. Zheng, Q.; Weng, Q.; Huang, L.; Wang, K.; Deng, J.; Jiang, R.; Ye, Z.; Gan, M. A new source of multi-spectral high spatial resolution night-time light imagery-JL1-3B. Remote Sens. Environ. 2018, 215, 300-312. [CrossRef]

31. Wei, S.; Jiao, W.; Long, T.; Liu, H.; Bi, L.; Jiang, W.; Portnov, B.A.; Liu, M. A Relative Radiation Normalization Method of ISS Nighttime Light Images Based on Pseudo Invariant Features. Remote Sens. 2020, 12, 3349. [CrossRef]

32. Sánchez de Miguel, A. Variación Espacial, Temporal y Espectral de la Contaminación Lumínica y Sus Fuentes: Metodología y Resultados. Ph.D. Thesis, Universidad Complutense de Madrid, Madrid, Spain, 2016.

33. Cheng, B.; Chen, Z.; Yu, B.; Li, Q.; Wang, C.; Li, B.; Wu, B.; Li, W.; Wu, J. Automated Extraction of Street Lights from JL1-3B Nighttime Light Data and Assessment of Their Solar Energy Potential. IEEE J. Sel. Top. Appl. Earth Obs. Remote Sens. 2020, 13, 675-684. [CrossRef]

34. Jiao, W.; Long, T.; Ling, S.; He, G. Study on Modeling and Visualizing the Positional Uncertainty of Remote Sensing Image. ISPRS-Int. Arch. Photogramm. Remote Sens. Spat. Inf. Sci. 2016, XLI-B2, 305-312. [CrossRef]

35. Portnov, B.A.; Saad, R.; Trop, T. Interactive Scenario-Based Assessment Approach of Urban Street Lighting and Its Application to Estimating Energy Saving Benefits. Energies 2021, 14, 378. [CrossRef]

36. Kline, R.B. Principles and Practice of Structural Equation Modeling, 4th ed.; Guilford Press: New York, NY, USA, 2016.

37. Davis, F.D.; Bagozzi, R.P.; Warshaw, P.R. User Acceptance of Computer Technology: A Comparison of Two Theoretical Models. Manag. Sci. 1989, 35, 982-1003. [CrossRef]

38. Gunzler, D.D.; Perzynski, A.T.; Carle, A.C. Structural Equation Modeling for Health and Medicine, 1st ed.; CRC Press: New York, NY, USA, 2021.

39. Guo, B.; Perron, B.E.; Gillespie, D.F. A Systematic Review of Structural Equation Modelling in Social Work Research. Br. J. Soc. Work 2009, 39, 1556. [CrossRef]

40. Little, T.D.; Card, N.A.; Slegers, D.W.; Ledford, E.C. Representing Contextual Effects in Multiple-Group MACS Models; Modeling Contextual Effects in Longitudinal Studies: New York, NY, USA, 2007.

41. Rigdon, E.E. Advanced Structural Equation Modeling: Issues and Techniques, 1st ed.; Psychology Press: New York, NY, USA, 1996.

42. Jason, T.N. Longitudinal Structural Equation Modeling: A Comprehensive Introduction, 1st ed.; CRC Press: New York, NY, USA, 2015.

43. Brown, T.A. Confirmatory Factor Analysis for Applied Research; The Guilford Press: New York, NY, USA; London, UK, 2006.

44. Kelloway, E.K. Using Mplus for Structural Equation Modeling; Sage: Thousand Oaks, CA, USA, 2015. 